NBER WORKING PAPER SERIES

\title{
TUSKEGEE AND THE HEALTH OF BLACK MEN
}

\author{
Marcella Alsan \\ Marianne Wanamaker \\ Working Paper 22323 \\ http://www.nber.org/papers/w22323
NATIONAL BUREAU OF ECONOMIC RESEARCH
1050 Massachusetts Avenue
Cambridge, MA 02138
June 2016, Revised June 2017

We thank the editor, Lawrence Katz, and four anonymous reviewers for constructive comments that improved the paper. For detailed feedback at an early stage of our work, we thank Nathan Nunn, Arun Chandrasekhar, Martha Bailey, Pascaline Dupas and William Collins. We are also grateful to John Parman, Achyuta Adhvaryu, Rebecca Diamond, Claudia Goldin, Melanie Morten, Mark Duggan, Mark Cullen, Melissa Dell, Nancy Qian, Ran Abramitzky, Rema Hanna, Grant Miller and seminar participants at NBER DAE, NBER Cohort Studies, University of Tennessee, Vanderbilt Health Policy, Carnegie Mellon and University of Pittsburgh Joint Seminar, University of Copenhagen, University of Pennsylvania Health Policy, ASSA 2016, PACDEV 2016, Berkeley Population Center, University of Chicago Harris School of Public Policy, Stanford Health Policy, University of California-Davis, University of Maryland Population Center, Stanford Social Science and History Workshop, University of South Carolina, Florida State University, University of Richmond, Highland Hospital of Oakland, Dartmouth College, Harvard Medical School, University of Michigan, University of California Berkeley, Simon Fraser University and CIREQ Montreal for constructive comments. We thank the CDC for providing access and the administrators at the Atlanta and Stanford Census Research Data Centers for their help in navigating the restricted data. We thank Michael Sinkinson, Martha Bailey, Andrew Goodman-Bacon and Walker Hanlon for sharing data and methods. Mario Javier Carrillo, Anlu Xing and Afia Khan provided excellent research assistance. The views expressed herein are those of the authors and do not necessarily reflect the views of the National Bureau of Economic Research.

NBER working papers are circulated for discussion and comment purposes. They have not been peer-reviewed or been subject to the review by the NBER Board of Directors that accompanies official NBER publications.

(C) 2016 by Marcella Alsan and Marianne Wanamaker. All rights reserved. Short sections of text, not to exceed two paragraphs, may be quoted without explicit permission provided that full credit, including $\odot$ notice, is given to the source. 
Tuskegee and the Health of Black Men

Marcella Alsan and Marianne Wanamaker

NBER Working Paper No. 22323

June 2016, Revised June 2017

JEL No. I14,O15

\begin{abstract}
For forty years, the Tuskegee Study of Untreated Syphilis in the Negro Male passively monitored hundreds of adult black males with syphilis despite the availability of effective treatment. The study's methods have become synonymous with exploitation and mistreatment by the medical profession. To identify the study's effects on the behavior and health of older black men, we use an interacted difference-in-difference-in-differences model, comparing older black men to other demographic groups, before and after the Tuskegee revelation, in varying proximity to the study's victims. We find that the disclosure of the study in 1972 is correlated with increases in medical mistrust and mortality and decreases in both outpatient and inpatient physician interactions for older black men. Our estimates imply life expectancy at age 45 for black men fell by up to 1.5 years in response to the disclosure, accounting for approximately 35\% of the 1980 life expectancy gap between black and white men and $25 \%$ of the gap between black men and women.
\end{abstract}

Marcella Alsan

Stanford Medical School

Center for Health Policy/PCOR

117 Encina Commons, Room 218

Stanford, CA 94304

and NBER

malsan@stanford.edu

Marianne Wanamaker

Department of Economics

University of Tennessee

524 Stokely Management Center

Knoxville, TN 37996

and NBER

wanamaker@utk.edu

A data appendix is available at http://www.nber.org/data-appendix/w22323 


\section{INTRODUCTION}

The Tuskegee Study became a symbol of their mistreatment by the medical establishment, a metaphor for deceit, conspiracy, malpractice, and neglect, if not outright genocide.

Corbie-Smith et al. (1999)

African-American men have the worst health outcomes of all major ethnic, racial, and demographic groups in the United States. ${ }^{1}$ Although recent trends have shown signs of improvement, particularly at younger ages, the gradients for older men are still sobering; the expectation of life for black men at age 45 is three years less than for their white male peers and five years less than for black women (Murphy 2013). Compared to other demographic groups, black men have higher death rates from chronic conditions such as HIV/AIDS, heart disease, and cancer, including lung, prostate, and colon (Kaiser Family Foundation 2007). Many factors contribute to such disparities, including lower income and education, lack of health insurance, and higher rates of disengagement from the labor force. But socioeconomic status is not fully determinant of these gaps (Adler et al. 1993; Cutler, Lleras-Muney, and Vogl 2011) and a growing qualitative literature suggests that mistrust of healthcare institutions partially contributes to these inequities. Yet empirical evidence on the causal role of medical mistrust for racial health disparities remains thin.

This study uses the historical disclosure of an unethical and deadly experiment, the Tuskegee Study of Untreated Syphilis in the Negro Male (TSUS), to identify the relationship between medical mistrust and racial disparities in health-related behaviors and health outcomes. For 40 years, between 1932 and 1972, the U.S. Public Health Service (PHS) followed hundreds of poor, black men in Tuskegee, Alabama, the majority of whom had syphilis, for the stated purpose of understanding the natural course of the disease. The men were denied highly effective treatment for their condition (most egregiously, penicillin, which became standard of care by the mid-1940s) and were actively discouraged from seeking medical advice from practitioners outside the study (Brandt 1978). Participants were subjected to blood draws, spinal taps, and, eventually, autopsies by the study's primarily white medical staff. Survivors later reported that study doctors diagnosed them with "bad blood" for which they believed they were being treated. Compensation for participation

1. For a comprehensive review of racial inequalities in U.S. medical care, see Institute of Medicine (2003). 
included hot meals, the guise of treatment, and burial payments. News of the Tuskegee Study became public in 1972 in an exposé by Jean Heller of the Associated Press, and detailed narratives of the deception and its relationship to the medical establishment were widespread. By that point, the majority of the study's victims were deceased, many from syphilis-related causes.

In the years following 1972, journalists, social scientists, and medical researchers have repeatedly pointed to the Tuskegee experiment as a reason African-Americans remain wary of mainstream medicine. For example, as HIV disproportionately ravaged black communities in the U.S., a number of observers conjectured that the Tuskegee Study's legacy had hampered public health education efforts in the black community, contributing to the epidemic's spread (Gaston and Alleyne-Green 2013). A recent resurgence of tuberculosis in Marion County, Alabama is similarly attributed (Blinder 2016). Qualitative research aimed at understanding the reluctance of black men, in particular, to participate in medical research or engage in preventive care often produces unprompted reference to Tuskegee (Corbie-Smith et al. 1999). In sum, the Tuskegee Study is an often-cited contributor to delays and avoidance in care seeking, wariness of public health campaigns, low participation in clinical trials, and overall worse health indicators among black men.

To empirically investigate whether the study's disclosure contributed to racial disparities in health and healthcare utilization in the years following 1972, we rely on a variety of survey and administrative data, including measures of trust in doctors from the General Social Survey (GSS) (Smith et al. 2015), health seeking behavior reported in the National Health Interview Survey (NHIS) (Minnesota Population Center 2012), and mortality data available by race, age group, gender, and cause from the Centers for Disease Control and Prevention (CDC 2014). We focus our attention on these measures for older (45-74) individuals, using other age groups as placebo tests since the mortality and health-seeking behavior of younger individuals is generally driven by acute conditions such as childbirth or trauma in which the needs for care are urgent and the benefits immediate. Because mistrust is more likely to discourage preventive and non-emergency medical care, we report results for both all-cause mortality and chronic disease mortality outcomes.

To generate testable predictions beyond those implied by the timing of the disclosure in 1972 , we use race and sex as additional treatment indicators. This approach is based, in part, on the supposition that individuals for whom the news of the Tuskegee Study's abuses was more salient should exhibit a more robust behavioral response. Economic models of trust formation and social 
identification (e.g., Tabellini 2008) and a vast psychology literature (e.g., Gutsell and Inzlicht 2010; Singer et al. 2006) indicate that individuals tend to be more affected by news if they can identify with the subject. We posit that individuals might perceive themselves at higher risk of medical mistreatment if they share socio-demographic characteristics with the study's victims. In this view, the Tuskegee abuses became a signal for how black men might expect the medical system to treat them. A simple Bayesian, multi-period model of belief formation regarding physician trustworthiness implies that, under certain conditions, agents having previous experience with the medical system, e.g., child-bearing women, are less dissuaded from seeking medical treatment by bad news, again implying stronger responses among men than women. ${ }^{2}$ The model and all supplementary materials are available in an Online Appendix.

As a final exposure to treatment, we interact these demographic characteristics with a locationbased measure of proximity: geographic distance to Macon County, Alabama, which contains Tuskegee. In doing so, we test whether black men living in closer proximity to the study's victims were more heavily influenced by the TSUS revelation. Such a pattern would be observed if, for example, individuals in closer geographic proximity believe the event is more instructive for how they may anticipate being treated by their local medical system. For an alternative proximity measure, we substitute the share of black migrant inflows from the state of Alabama to an individual's local geography. The Great Migration was characterized by strong chain migration and by substantial amounts of return migration such that individuals living in locations with higher rates of black migration from Alabama would have experienced a lasting information network, in addition to any additional salience arising from these connections.

We test these hypotheses using an interacted difference-in-difference-in-differences framework that captures post-1972 changes in the racial and gender gaps in healthcare utilization and health outcomes for those in varying proximity to the event. Whenever feasible, we condition on a rich set of control variables found to be correlated with individual health seeking behavior, including education (Aizer and Stroud 2010), income (Deaton 2002), marital status (Holt-Lunstad, Birmingham, and Jones 2008), and urbanization. Race-gender-location, race-gender-time and location-time fixed effects non-parametrically control for time-invariant factors that influence outcomes for a spe-

2. In our model of medical mistrust, we consider Bayesian updating as the benchmark, although behavioral models could deliver similar results (e.g. Becker and Rubinstein 2011). 
cific demographic group in a given locale and for changes in public health and other government policies that might have differentially affected members of each group in each year. The finest level of geography observable in the utilization regressions is a respondent's state, and we use observations at the county or state economic area level for mortality outcomes. We focus on the short- and medium-term impact of the disclosure on health behaviors and outcomes; given the data limitations, persistent causal impacts are more difficult to identify.

Our estimates imply that a one-standard deviation increase in geographic proximity to Macon County, Alabama, reduced utilization of routine care (outpatient physician contacts) among older black males by 0.90 interactions per year, a $22 \%$ reduction in utilization relative to the pre-disclosure mean value for black men. These utilization effects are driven by the behavior of black men with lower levels of education and income. We also find weaker evidence of a reduction in the probability that black men were admitted to the hospital, though their length of stay was significantly longer, consistent with more advanced disease upon presentation. Mortality outcomes indicate that a one standard deviation increase in geographic proximity to Tuskegee was associated with a spike in the post-1972 age-adjusted mortality penalty for black men of 4 log points. Our estimates imply that the Tuskegee Study disclosure contributed to widening health disparities between 1970 and 1980, accounting for approximately 35\% of the 1980 life expectancy gap between black and white men and $25 \%$ of the gap between black men and women.

An alternative explanation for our findings is that access to healthcare was deteriorating for blacks relative to whites in this period, particularly in the South, and black men were precluded from obtaining routine medical care regardless of their underlying demand. But controlling for public health expenditures and for the availability of hospital services has little effect on our estimates, and this alternative explanation is inconsistent with other research concluding that access to health services and health outcomes for black Americans improved substantially in the years immediately after the Civil Rights Act (Goodman-Bacon 2015; Almond, Chay, and Greenstone 2006; Cascio and Washington 2014). Our results indicate that the Tuskegee revelation stalled the overall pattern of convergence for older black men, producing a drag on healthcare utilization for this specific demographic group and contributing to an abrupt divergence in their mortality patterns.

We pursue a number of strategies to provide further evidence that the correlations we find are indeed causal. First, the results we find are specific to black men; coefficient estimates for the 
post-1972 treatment effect of being "black and female" or "white and male" in closer proximity to Macon County, Alabama, are generally not economically or statistically significant, do not exhibit an observable break in 1972, and are often opposite-signed to the main treatment effects. In additional tests, we show that our findings are robust to estimation on a within-South sample and that the baseline coefficients for mortality (utilization) based on geographic proximity to Macon County, Alabama, are larger (smaller) than $96 \%$ of placebo tests substituting proximity to all other geographies in the data. Thus the effects we measure are specific to black men and to geographic proximity to central Alabama, not to a post-1972 condition affecting the South overall.

Finally, to evaluate whether the behavioral responses we observe are driven by medical mistrust, we use survey data from the 1998 wave of the GSS on whether individuals trust a doctor's judgment and whether they suspect that the medical establishment will deny them necessary treatment or services. When we interact race and gender indicators with a measure of the distance of an individual from Macon County, Alabama, we find the same geographic gradient apparent in our baseline utilization and mortality results. This geographic gradient in mistrust is not present for general mistrust as revealed in the respondents' answers to other survey questions.

This paper builds on and contributes to several literatures in economics. First, our findings elucidate factors influencing healthcare demand and medical outcomes among minorities in the United States and deepen our understanding of how this watershed event affected the relationship between black Americans and the U.S. healthcare system. Second, and more broadly, our study is motivated by the theoretical contributions of Guiso, Sapienza, and Zingales (2008) regarding the transmission and updating of beliefs and empirical work by Nunn and Wantchekon (2011) regarding the role of previous exploitation in shaping interpersonal mistrust in Africa. Our findings also connect to rich empirical evidence on the importance of trust for economic development (Knack and Keefer 1997; Fafchamps 2006; Greif 1989). Finally, these findings shed light on questions in development economics regarding low demand for products that have been shown to improve health (Dupas 2011; Chapter 3 of Banerjee and Duflo 2011). The findings presented herein suggest that historical exploitation and its enduring impact on beliefs may explain some of the uptake paradox. 


\section{Context}

The following section places the study in historical and medical context by providing background on the pathology of syphilis and the TSUS experiment, prior literature on the legacy of Tuskegee, and health patterns across demographic groups in the years surrounding the disclosure.

\section{II.A. Background on the Tuskegee Study}

The Tuskegee Study was designed to trace the course of untreated syphilis in black men. The organism that causes the disease is related to that causing Lyme disease, and both bacteria manifest themselves in stages. The first stage of sexually acquired syphilis is often an ulcer, followed by a full body rash that includes the palms and soles. However, it is the tertiary (or late-stage) syphilis that inflicts the most damage. The third stage is characterized by gummas (syphilitic tumors teeming with the bacteria) which coalesce and eat away at bone (frequently the nasal bridge) as well as other organs and show a predilection for the arch of the aorta often leading to hemorrhage. Neurosyphilis (an attack on the nervous systems) presents in late-stage syphilis with paresis, gait disturbance, blindness, and dementia (Mandell, Bennett, and Dolin 2009). ${ }^{3}$

According to Jones (1992), much of the natural history of syphilis outlined above was known at the time the study commenced:

"The germ that causes syphilis...and the complications that can result from untreated syphilis were all known to medical science in 1932 - the year the Tuskegee Study began. Since the effects of the disease are so serious, reporters in 1972 wondered why the men agreed to cooperate. The press quickly established that the subjects were mostly poor and illiterate, and the PHS had offered them incentives to participate."

These incentives included physical exams, hot meals, and burial stipends that would be paid to their survivors. Most of the men also believed they were receiving some form of treatment. Approximately 600 black men (approximately two-thirds of whom had syphilis) were recruited to the study using these techniques and followed passively for forty years while the disease took its toll.

3. Syphilis can also be transmitted mother to child and cause severe congenital problems, including stillbirth. 
In 1972, news of the Tuskegee Study was leaked to the press and quickly spread, including reporting from the New York Times and the Los Angeles Times, via the Associated Press wire, on broadcast television, via congressional hearings, and, of course, by word of mouth. The study was halted that same year, but few of the original test subjects were alive and dozens of their wives and children had been infected (Heintzelman 2003). Medical historian Allan Brandt (1978) summarizes the study as follows: "In retrospect the Tuskegee Study revealed more about the pathology of racism than the pathology of syphilis; more about the nature of scientific inquiry than the nature of the disease process. . . . The degree of deception and the damages have been severely underestimated." Those damages may include a legacy of medical mistrust among black Americans. The Final Report of the Tuskegee Syphilis Study Legacy Committee (1996) noted that "the Study continues to cast a long shadow over the relationship between African-Americans and the biomedical professions," and was "a significant factor in the low participation of African-Americans in clinical trials, organ donation efforts, and routine preventive care."4

Despite the Committee's conclusions, the empirical evidence of a link between the Tuskegee Study and medical mistrust has been mixed and suffers from several limitations. First, and perhaps most crippling, all quantitative and qualitative studies of the relationship between medical mistrust and awareness of Tuskegee's abuses are dated 20 or more years after 1972. By this time, the link between medical mistrust and knowledge of Tuskegee may have faded for a number of reasons, including a socialization of mistrust without an accompanying socialization of the relevant history. ${ }^{5}$ Second, a correlation between medical mistrust and knowledge of the Tuskegee Study provides no information on the direction of causation; distrustful individuals may do more to collect information on past abuses. Third, the extant literature focuses on participation in clinical trials rather than medical mistrust per se. Although these outcomes are likely to be correlated, it is the mistrust of care providers that directly impacts health conditions. Finally, samples used in these studies are frequently restricted to particular geographies.

4. This lack of minority representation in clinical trials may have important spillover effects, including on the speed and direction of innovation for ailments that heavily afflict their communities. See Hamilton et al. (2016) for a structural estimation of these losses.

5. Vann Newkirk II (2016) highlights the cultural role of Tuskegee, even in the absence of specific details, saying: "Like me, several other black men that I interviewed throughout the rural South were either inculcated from birth or from experience living in 1972 with the idea that the American health-care system is not for them. Young boys and old men felt it alike, and even if the Tuskegee Study was not known by name, it was a definite part of a vivid shared cultural memory. References to injection of 'bad blood', government research, or conspiracies about HIV were clearly influenced by details of Tuskegee, even if the details weren't always quite right." 
With these qualifications in mind, the earliest quantitative study on this topic is from 1994 (22 years following the disclosure). Researchers surveyed residents of Jefferson County, Alabama (Green et al. 1997). Although 55\% of the sample held knowledge of the Tuskegee Study, and the rate was no higher for black men and women than for whites, knowledge of the study by black men increased with age, reaching $74 \%$ for those aged 46-64 (who would have been 24-42 at the time of the study). The sample's age distribution differed substantially by race, and the survey write-up does not include a conditional relationship between race, age, sex, and knowledge of Tuskegee, nor does it give a conditional relationship between willingness to participate in health research and Tuskegee knowledge. But unconditional cross tabulations indicate that $27 \%$ of black men were less interested in participation as a result of the study, compared to $20 \%$ of black women and $10 \%$ of whites. Among all African Americans (male and female), this disinterest was highest for individuals with a high school degree, but no college, and among those aged 31-65. These survey responses also indicate significant racial gaps in respondents' perceptions of the fairness of medical care and research. ${ }^{6}$

In addition to the Green et al. study, Brandon, Isaac, and LaVeist (2005) surveyed 401 black and white adults living in Baltimore, Washington D.C., and New York City in 2003 and found that blacks were far less likely to report knowledge of Tuskegee than whites (74\% vs. 25\%), a statistic uncovered by White (2005) in his critique of their paper. This result, along with the survey's high refusal rate, led White to cast doubt on the study's methods. Brandon et al. also reported that blacks with knowledge of the study were $50 \%$ more likely to believe the PHS researchers injected the men with syphilis ( $75.3 \%$ vs. $52.8 \%$ ) and to believe Tuskegee could "occur today" (76.6\% vs. $47.2 \%$ ). In this study, medical mistrust was positively related to black race, male sex and lower education, but not significantly related to knowledge of the Tuskegee Study. Shavers, Lynch, and Burmeister (2002) found the opposite: a greater unwillingness to participate in medical research among blacks who knew about the study. The Tuskegee Legacy Project of 2003, which interviewed black, white, and Hispanic men and women, found that blacks were more likely to have a higher "guinea pig fear factor" score than whites and were more likely to have knowledge of the Tuskegee Study than whites or Hispanics (56.2\% vs. $38.5 \%$ and $24.3 \%$, respectively) (McCallum et al. 2006).

6. For example, $75 \%$ of black men believed that "African Americans are more likely to be treated poorly in health research studies" compared to $58 \%$ of black women and $37 \%$ of whites. Sample sizes here are quite small, however, so caution is warranted. 
As best we can ascertain, Freedman (1998) is the earliest qualitative research on the relationship between medical research mistrust and the Tuskegee Study. Freedman asserts that the Tuskegee legacy is not enough to fully explain racial differences in participation in medical research, yet cites interviewees who explicitly and vividly expressed their unwillingness to participate in medical studies in connection with the Tuskegee Syphilis experiment. Additional qualitative evidence links mistrust associated with the Tuskegee Study with take-off of the HIV/AIDS epidemic in minority communities. On May 12, 1992, the New York Times published poll results wherein blacks were more likely to believe in conspiracy theories related to HIV/AIDS, including that the virus was a genocide tool designed to limit the number of blacks in America. (These results have been replicated many times over.) According to Quinn (1997), resulting letters to the editor "clearly placed the origin of such attitudes within the historical context of the Tuskegee Syphilis Study". ${ }^{7}$ At the height of the HIV/AIDS crisis in the U.S., health publications implored medical professionals to directly confront these conspiracy theories with facts, and correct the common misconception that the Tuskegee abuses included infecting study subjects with syphilis. "Public health professionals must recognize that Blacks' belief in AIDS as a form of genocide is a legitimate attitudinal barrier rooted in the history of the Tuskegee Syphilis Study" (Thomas and Quinn 1991).

In addition to specific Tuskegee legacy studies, the public health literature provides ample documentation that being black and male is an important predictor of health disparities, including those in life expectancy, survival rates within disease category, and health-promoting behavior. Black men are less likely to know their cholesterol levels, engage in blood pressure monitoring, or otherwise benefit from early detection of chronic conditions than their white male peers (Sandman, Simantov, and An 2000; Viera, Thorpe, and Garrett 2006). Although reasons for these disparities are multifactorial, the legacy of medical exploitation (represented in part by the Tuskegee Study) has led to research on whether medical mistrust is particularly heightened among black men (Carlson and Chamberlain 2004). Indeed, black men exhibit higher levels of medical mistrust which are correlated with reduced probabilities of routine, preventive, and early-stage disease care. ${ }^{8}$ Medical

7. Additional beliefs were that "HIV was deliberately created in a laboratory in order to infect black people, that AZT is a plot to poison them, that condom distribution campaigns are a scheme to reduce the number of black babies, and that needle distribution programs are a plot to encourage drug abuse," (Quinn 1997). Similar Tuskegeeattributed mistrust related to the origins of the HIV virus emerged in a 1996 ABC News 20/20 forum and in a 1997 Atlanta-based forum audience.

8. The life expectancy gap between black and white men can be substantially reduced by controlling for stage 
mistrust among black men is also correlated with poor compliance with treatment plans, conditional on diagnosis, for a range of diseases including HIV/AIDS, cancer, and hypertension. ${ }^{9}$

\section{II.B. Patterns of Healthcare Utilization and Mortality}

Prior to the Tuskegee experiment revelation, the 1960s marked an era of rapid convergence in healthcare access and utilization for black Americans relative to whites. Hospitals gradually integrated over the 1950s and early 1960s, a process that culminated not with the Civil Rights Act of 1964, but with President Lyndon Johnson's insistence that any hospital receiving Medicare funding fully desegregate by July 1966. This process was quicker in the North than in the South; separate hospital wings were present in $75 \%$ of hospitals in the South as late as April of 1966. Still, full compliance appears to have been achieved by July of the same year. These decades also witnessed expansions in public health insurance coverage and services, some of which favored black Americans, including the establishment of Medical Assistance for the Aged (a precursor to Medicare), establishment of and expansions in Medicare and Medicaid (Goodman-Bacon 2015), local health center construction (Bailey and Goodman-Bacon 2015), and the expansion and funding of public hospitals.

By 1970, black Americans had gained substantial ground in terms of healthcare utilization, even if the quality of the services they acquired lagged behind their white peers. ${ }^{10}$ Using data from the NHIS, among individuals ages 45 to 74, the percentage of black women who did not have recent contact with a medical professional declined between 1964 and 1971 by about 6 percentage points. The improvements for black men were similarly impressive; the same metric declined by 8 percentage points. These gains were three to four times as large as those experienced by white males and females over the same time period. ${ }^{11}$ The convergence of black and white healthcare

at diagnosis. See American Cancer Society (2008) and Silber et al. (2014). For evidence on these racial gaps, see Boulware et al. (2003); Wiltshire, Person, and Allison (2011); and Hood et al. (2012).

9. In a 2016 study of low adherence to antiretroviral treatment among HIV-positive black men, researchers documented that $63 \%$ of the study's subjects held a "conspiracy belief", for example that the federal government was responsible for HIV's introduction into the black population. These beliefs, in turn, were associated with a reduced likelihood of adhering to a physician-prescribed treatment regimen (Bogart et al. 2016). See also Halbert et al. (2009), Kayaniyil et al. (2009); and Laveist, Nickerson, and Bowie (2000).

10. Blacks were more likely than whites to utilize public and community-based healthcare resources, including charity clinics, public health departments, community health centers, and city and county hospitals and less likely to make use of private and non-profit hospitals. Some of this difference was the result of rapid suburbanization of the white population (Byrd and Clayton 2002, p. 391).

11. The level of utilization for black (and white) men is lower than for women in every period. Note that we do 
utilization rates in the years prior to the Tuskegee disclosure was closely mirrored by convergence in mortality rates. Using CDC-provided annual county-level mortality statistics by age, race, and gender, as described above, we plot the racial difference in age-specific mortality rates (ASMR) (black minus white) for both men (solid line) and women (dashed line) in Figure I. Panels A and $\mathrm{B}$ demonstrate that, for infants and children 1 to 4 years of age, there was a marked reduction in racial health disparities that continued, uninterrupted, after the 1972 disclosure. But the pattern for adult mortality is starkly different. Panels $\mathrm{C}$ and D plot the same data for adults aged 55-64 and 65-74. At these ages, convergence at the beginning of the period is followed by a striking divergence in the mortality rates for black men relative to white men beginning in the early 1970s, a pattern which is not reflected in the differences between black and white women. The mortality patterns for other ages (contained in Appendix Figure A.2) mimic those for infants and children. ${ }^{12}$ Unlike younger ages, where parental behavior (for early childhood) and unintentional injuries (for young adults) play key roles in determining mortality, premature and preventable mortality in older adults is more frequently driven by health behaviors and physician involvement, including timely diagnosis and management of illness. To facilitate comparisons across age groups, the mortality rates represented by Figure I are those from all causes of death; specific cause-of-death is available in the underlying data and utilized later in the paper. These stark mortality patterns for black men relative to both black women and white men motivate the paper's focus on health behaviors and outcomes of black men in particular.

\section{DATA}

The paper's empirical approach focuses on changes in health-seeking behavior and health outcomes as a result of the Tuskegee disclosure. We measure health-seeking behavior using data on healthcare utilization from the NHIS. The survey is a repeated cross-sectional sample of Americans which began in 1963. The survey is taken by household visit, and we use the individual-level respondent data in our analysis. We rely on a harmonized data source, the Integrated Health

not have a continuous series of outpatient utilization data in the pre-1969 period.

12. The Appendix also contains figures for Southerners alone (Appendix Figure A.1). In Appendix Figure A.2, younger black men exhibit an increase in relative mortality beginning in the 1980s. This is likely due to the evolving HIV/AIDS crisis in this community. Appendix Section V.A. contains more detail. 
Interview Series (IHIS), provided by the University of Minnesota, which is based on the NHIS public-use data (Minnesota Population Center 2012). Consistent, harmonized responses regarding the utilization of medical services are available from 1969. ${ }^{13}$ The public-use samples are stripped of geographic identifiers necessitating the use of restricted access for these data from the National Center for Health Statistics (NCHS). ${ }^{14}$ One important caveat with using these data is that PHS, the same entity that carried out the Tuskegee Study, sponsored the survey, although the interviews were conducted by the U.S. Census Bureau. If mistrustful individuals refused to answer the survey, our estimates may represent attenuated behavioral responses. In a simple difference-in-differencein-differences (DDD) specification where we regress the NHIS sample weight for each individual on year fixed effects, an indicator for black, an indicator for male, an indicator for black-male, and an indicator for post-1972 interacted with each of the demographic indicators, we find that the survey weights for black men in the sample after 1972 rose by a statistically insignificant $0.3 \%$.

Each individual in the survey self-reported the interval since their last doctor's visit or physical, the number of physician visits and other physician interactions (including phone calls) in the last 12 months, as well as the frequency and duration of hospital admissions. The data also contain detailed demographic information, including age, family structure, income, education, and veteran status. $^{15}$ As discussed previously, we focus on men aged 45 to 74 to capture the effects on men (and women) in the age range most likely to benefit from preventive and early-stage disease care. We distinguish between non-veteran and veteran men given differences in their previous physician interactions. Our baseline utilization results are for non-veteran males, and we present results by veteran status later in the paper.

Because morbidity data is difficult to interpret in this context (disease diagnosis would generally require a physician's visit), we rely on separate mortality data to assess whether the changes in

13. The question we use regarding outpatient interactions is unchanged between 1969 to 1981 . In 1978 the race categorization changed, with mutiple categories included, making 1977 a natural stopping point. But we have also extended our analysis to 1981 (the year the question on doctor visits changes and harmonization is no longer possible) and obtain similar (though not disclosed) results. Inpatient (hospital) utilization data is available prior to 1969 and the broad patterns are discussed in Section II.B. Our results are robust to the inclusion of these earlier data. IHIS is now known as IPUMS Health Surveys: NHIS.

14. We accessed the IHIS harmonized data, with location-based treatment variables (geographic proximity and migration shares) attached, inside Census Research Data Centers (RDCs) at Atlanta and Stanford. In later years, the NHIS data have been linked to mortality files, but these linked data are not available for our study period.

15. The NHIS data do not contain consistent measures of individual health insurance coverage over our time period; however, in all mortality regressions we control for local, time-varying Medicare and Medicaid expenditures, interacted with race and gender. Because phone calls to medical providers were counted as physician interactions, all NHIS regressions control for whether the household has a telephone. 
beliefs and behaviors which we document below translate into an effect on health. In doing so, we follow a sizable literature that uses mortality to assess the effectiveness of health interventions. ${ }^{16}$ County-level mortality statistics by age, race, and gender are available from the CDC for each year between 1968 and 1988. We merge population data for the same period from the CDC to calculate mortality rates by age group, race, and gender (CDC 2014). Because some U.S. counties have small black populations, the per-year mortality counts in some places are quite low, and sometimes zero. Mortality rates based on a sparse number of events exhibit a large amount of random variation (Curtin and Klein 1995), thus we follow advice from NCHS and aggregate over space and time, combining annual county-level mortality counts to the state economic area (SEA) level and measuring biennial mortality rates. ${ }^{17}$ We do not observe veteran status in the mortality files.

Our baseline results are for both age-adjusted all-cause and age-adjusted chronic-cause mortality. Chronic causes include cardiovascular disease (including hypertension and stroke), cancer, smoking-related respiratory disease, ill-defined conditions and ongoing symptoms, gastrointestinal disorders, and diabetes. Chronic mortality therefore includes the leading causes of death for this cohort and represents diagnoses for which therapies and interventions by health professionals could plausibly prevent or delay mortality. ${ }^{18}$ We use age-adjusted mortality rates to account for differences in age structures across groups. ${ }^{19}$ Since the impact of the Tuskegee revelation might affect mortality with a lag and last longer than the impact of utilization, we include mortality rates from 1968 to 1987 in our main analysis. ${ }^{20}$

16. Recent examples include Almond, Chay, and Greenstone (2006); Alsan and Goldin (2015); Bhalotra and Venkataramani (2011); Bailey and Goodman-Bacon (2015); and Goodman-Bacon (2015).

17. State economic areas are groups of counties reflecting relatively homogenous areas within states. Results using county-level and annual mortality rates are in Appendix Table A.5.

18. Some examples include blood pressure and glucose control for the management and prevention of cardiovascular and diabetic complications such as heart attack, stroke, and kidney failure, as well as counseling on prevention, early detection, and treatment of cancers. See Appendix Section IV for a discussion of medical and public health innovations over this time period.

19. Briefly, to construct age-adjusted rates, age-specific mortality rates, calculated as deaths per 1000 relevant at risk population, are weighted by a reference population. We follow the demographic literature and use the standard 1940 population for weighting. See the Appendix for further details.

20. After 1987, the paper's conclusions are likely to be compromised by the evolving HIV/AIDS epidemic. But in the 1981-1987 period, HIV/AIDS was a nascent health threat, particularly among older black men. In this period, there were roughly 9,000 AIDS-infected men older than 45, of which perhaps $25 \%$ were black (CDC 2001). Young people were at higher risk of acquiring HIV, and by 1994 AIDS had become the leading cause of death among black males aged 25-44. This increased mortality among younger black males in the late 1980s is apparent in Appendix Figure A.2. 


\section{Estimating Equation and Identification}

Our main specification is an interacted DDD comparing differences across race (first difference) and gender (second difference) before versus after the study disclosure (third difference), interacted with a continuous, location-based measure of salience, either geographic proximity to Macon County, Alabama, or the share of black migrants originating from Alabama.

Why might the disclosure of the Tuskegee Study fuel mistrust in medicine particularly among black men? First, as discussed in the introduction, models of social identification and studies of empathy demonstrate that individuals are more responsive to injustices perpetrated against their own group and more empathetic to individuals in closer "proximity" to themselves. Distance between agents, as described by Tabellini (2008), "could refer to geography, but also to social or economic dimensions such as religion, ethnicity and class." Second, in recent work on the formation of trust, psychologists have noted that men tend to form collective trust (with "categories" of people rather than individuals), while women form individual-specific relational trust (Maddux and Brewer 2005). Third, even in the absence of differences in trust formation, ceteris paribus black women would have had more experience with the healthcare system through previous childbirth experiences, and this experience may have inoculated them against the Tuskegee Study revelation. Fourth, men have more elastic demand for health services (Vaidya, Partha, and Karmakar 2012; Thanakijborisut 2015) and thus are more easily dissuaded from visiting a physician. Finally, and perhaps obviously, the victims of the Tuskegee Study were black men. The disclosure detailed how the medical establishment purposefully selected and abused black men and may have therefore revealed to black men information about how they might expect to be treated.

Empirically, we build on Tabellini's description of "distance" by employing both race and gender as treatment indicators, as well as one of two location-based treatment measures. ${ }^{21}$ Our primary measure is linear geographic proximity to Macon County, Alabama (Figure II; Panel A), supported by the linear relationship between post-1972 mortality changes and distance, as discussed below. ${ }^{22}$

21. The Appendix contains a fully-specified model of how prior beliefs, prior experience with the medical profession, shared characteristics with the Tuskegee study subjects, and proximity to the study interact to determine healthseeking behavior

22. Data from the 1979 Survey of Black Americans support the notion that black men from the South identified more with the men from the study. When asked "how close does the respondent feel to black people who are poor", $78 \%$ of black men born in the South answered they felt "very close" compared to $65 \%$ of men born elsewhere (Jackson and Gurin, 1999). We thank Trevon Logan for pointing out this source. As another example, although the Rodney 
This continuous proximity metric creates concentric circles of equal proximity around the impact point of Tuskegee, Alabama. Although we remain agnostic regarding the precise mechanism through which geographic proximity affects behavior, we note that geography may capture an identification or empathy response as discussed above. Alternatively, this proximity metric may also reflect information contained in the signal if, for example, individuals at greater geographic distances do not believe that the Tuskegee experiment disclosure provided relevant information regarding the trustworthiness of their local medical practitioners. ${ }^{23}$

As an alternative measure of salience, we use the fraction of black migrants to a particular state or SEA from the state of Alabama (Figure II, Panel B). (We drop Alabama observations from the sample in this analysis.) The Tuskegee disclosure followed several decades of large-scale migration, particularly among African-American males, and we hypothesize that individuals in locations with larger numbers of incoming migrants from Alabama will also find the study's revelation more salient. We take advantage of the complete count version of the 1940 U.S. Census, which contains a question about 5-year migration patterns with detailed geography measures, to calculate this statistic. $^{24}$ Migration rates are highest in young adulthood; thus, the migration patterns from 1935-1940 will be reflective of the origins of individuals aged 45-74 in 1972. The 1940 Alabama migration rates are additionally relevant as migration patterns are roughly stable over time, making the 1940 patterns a good proxy for patterns in the years subsequent.

King beating, which took place in March 1991, was widely publicized in many media markets, opinions on the police force shifted most markedly for black men. Though we lack geographic identifiers in the survey data, comparing 1989 and 1992 polling data, the percentage of people who disagree with the statement: "These days police in most cities treat Blacks as fairly as they treat Whites" jumped $18 \%$ among black men, $7 \%$ among black women, and declined among whites (ABC 1992; NBC 1989).

23. We exclude the SEAs containing Los Angeles and San Francisco from the analytic sample. These two cities hold most of the black population in the West region, and they are more connected to Alabama (via migration) than our distance-based proxy for study salience would suggest (see Appendix Figure A.7). Our migration-based results are robust to the inclusion of these two cities. See Appendix Table A.5, Column (1).

24. Using later census years would preclude us from using the detailed geographic information publicly available for 1940. We normalize by black migrants for two reasons. First, doing so gives a measure of what percentage of new information is coming from Alabama. (If the denominator was the black population, for example, the new information measure would be diluted.) Second, and more importantly, we only observe the migration variables in the five year period of 1935 to 1940 . But the migration of this generation of men extended from 1918 up through 1960. The patterns of migration were persistent over time, so even though the 1935-1940 measure is not an accurate measure of the absolute number of migrants, the relative measure (those from Alabama divided by all migrants) is a good proxy for how connected the stock of black residents in 1972 would have been to Alabama, given several decades of migration preceding 1972. 


\section{IV.A. Motivating Difference-in-Differences Estimates}

Recall from Figure I that black male mortality was converging relative to white men from 1968 through the early 1970s before diverging thereafter. We use a simple difference-in-differences (DD) framework to explore these changes. Specifically, we compare the post-1972 age-adjusted mortality rates from chronic disease of older black men relative to their white male or black female peers across SEAs grouped into $K$ bins of 150 kilometers of distance from Macon County, Alabama. ${ }^{25}$

To estimate the post-1972 mortality penalty for older black men compared to white men in each bin, we estimate a set of $\beta^{k}$ coefficients from the equation below. Group-specific, chronic cause mortality is reflected by $Y_{r a t}^{k}$ where $a$ reflects the SEA of residence at time of death, $t$ is year of observation, and $r$ denotes the race of the group:

$$
Y_{r a t}^{k}=\alpha+\beta^{k}\left(\mathbf{I}_{r}^{\text {black }} \cdot \mathbf{I}_{t}^{\text {post }}\right)+\gamma^{k}\left(\mathbf{I}_{t}^{\text {post }}\right)+\phi_{a, \text { black }}+\varepsilon_{\text {rat }} \quad \text { for } k \in[1, K]
$$

$\mathbf{I}_{r}^{\text {black }}$ and $\mathbf{I}_{t}^{\text {post }}$ are binary indicators for black and post-1972 observations, respectively, while $\phi_{a, b l a c k}$ is an SEA-by-race fixed effect common across all years. Regressions are weighted by the relevant population in each SEA (e.g. 45-74 year old men for the all-male sample).

In this equation, $\beta^{k}$ captures the post-1972 effect of being a black male relative to white men, controlling for time-invariant differences in black and white male mortality in each SEA and for a general post-1972 mortality effect $\left(\gamma^{k}\right)$. If mortality rates for black men had continued to converge in the post-1972 period, we would measure a value of $\beta$ less than zero in each bin. Alternatively, stalled convergence would generate a value of $\beta$ greater than or equal to zero. As anticipated, given the results in Figure I, the full-sample $\beta$ (across all values of $k$ ) is positive and significant, indicating post-1972 divergence in mortality for older black men relative to their white peers of approximately $5.3 \mathrm{log}$ points. This estimate is plotted as a thick line, and both the estimate and 95\% confidence interval are reported in the heading for Figure III, Panel A.

Yet this average treatment effect of being a black male after 1972 masks significant heterogeneity. We find a strong geographic gradient in the value of $\beta$ along a measure of distance from Macon County, Alabama, with locations closer to Macon County showing stronger evidence of divergence.

25. Age-adjusted mortality rates for older adults (ages 45-74) are measured at the level of each SEA (denoted $a$ ) for each race $(r)$ and gender $(g)$ combination: black males, black females, white males, white females. Bins in the middle of the country with few older black men were paired. 
In Figure III, Panel A, we plot the value of these coefficients by bin, as well as a (thin, dashed) line of best fit. Black men in close proximity to Tuskegee saw an increase in relative chronic mortality of about $10 \log$ points, and the effect declines with distance.

To compare the post-1972 experience of black men to that of black women, we estimate a separate set of $\beta^{k}$ coefficients on a sample of black mortality rates, male and female, replacing indicators for black with indicators for male in equation (1). ${ }^{26}$ As indicated in the header for Panel B of Figure III, black male age-adjusted chronic mortality increased relative to black female mortality by a statistically significant $9.1 \log$ points after 1972. Here, the geographic gradient is even more apparent; the value is $17 \log$ points in locations closest to Tuskegee and again declines with distance.

These temporal and geographic mortality patterns for black men are not mirrored in other sub-groups. In Panel C of Figure III, we estimate equation (1) on an all-female sample. In this case, $\beta^{k}$ coefficients reflect the post-1972 convergence or divergence experiences of black women in each geographic bin. Consistent with Figure I, we find that black women continue to converge on their white peers after 1972, and the average estimated value of $\beta$ is $-9.2 \log$ points. Moreover, the geographic gradient in these results is upward-sloping, indicating that black women in closer proximity to Macon County were converging more quickly than their peers further afield. A similar exercise in Panel D examines the experience of white men relative to white women. Overall, the gap in age-adjusted chronic mortality for white men relative to white women fell by 5.4 log points, perhaps as white men became beneficiaries of medical technologies and advice that spread over this time period. (See Appendix Section IV.) We see little evidence that proximity to Macon County was detrimental for the health of white men in the post period. Although the dotted line of best fit is downward sloping, this result is driven by convergence occurring at distances beyond 2000 kilometers from Alabama; estimated values of $\beta^{k}$ within the South show no geographic gradient.

To assess whether the observed geographic patterns in health outcomes for black men compared to black women and white men emerged in the post-1972 period, we look for the same patterns in the years prior to the Tuskegee disclosure, instituting a false definition of $\mathbf{I}^{\text {post }}$ in this set of observations. We plot estimates of $\beta$ for the same set of distance buckets in Panels $\mathrm{E}$ and $\mathrm{F}$ of

26. The estimating equation is $Y_{g a t}^{k}=\alpha+\beta^{k}\left(\mathbf{I}_{g}^{\text {male }} \cdot \mathbf{I}_{t}^{\text {post }}\right)+\gamma^{k}\left(\mathbf{I}_{t}^{\text {post }}\right)+\phi_{\text {a,male }}+\varepsilon_{\text {rat }} \quad$ for $k \in[1, K]$, where $g$ reflects gender. 
Figure III, defining $\mathbf{I}^{\text {post }}$ to be one for all observations after the mid-point of the pre period. These falsification tests indicate no geographic gradient in the estimates of $\beta$, and the slope of the line of best fit is flat for both the all-male and all-black specifications.

\section{IV.B. Baseline Estimating Equations}

The geographic gradients documented in Figure III motivate a DDD estimator which interacts differences over time, race, and gender with a continuous measure of proximity to Macon County, Alabama. We denote this proximity measure $P_{j}$ where $j \in s, a$ represents measurement at the state or SEA level, respectively. To facilitate interpretation of regression coefficients, geographic distance is transformed to proximity to Macon County, Alabama, in thousands of kilometers. ${ }^{27}$ The relevant estimating equation for healthcare utilization for individual $i$ of race $r$ and gender $g$ measured in state $s$ at time $t\left(Y_{\text {igrst }}\right)$ is:

$$
\begin{aligned}
Y_{\text {igrst }}= & \alpha+\beta_{1}\left(P_{s} \cdot \mathbf{I}_{t}^{\text {post }} \cdot \mathbf{I}_{r}^{\text {black }} \cdot \mathbf{I}_{g}^{\text {male }}\right)+\beta_{2}\left(P_{s} \cdot \mathbf{I}_{t}^{\text {post }} \cdot \mathbf{I}_{g}^{\text {male }}\right)+\beta_{3}\left(P_{s} \cdot \mathbf{I}_{t}^{\text {post }} \cdot \mathbf{I}_{r}^{\text {black }}\right) \\
& +\mathbf{X}_{i t}^{\prime} \Phi+\theta_{\text {rgt }}+\phi_{\text {rgs }}+\tau_{s t}+\varepsilon_{\text {igrst }} .
\end{aligned}
$$

For mortality outcomes, the vector of covariates $(\mathbf{X})$ must be treated differently, and the estimating equation for the mortality rate of groups characterized by race $r$ and gender $g$ in SEA $a$ at time $t$ is:

$$
\begin{aligned}
Y_{\text {grat }}= & \alpha+\beta_{1}\left(P_{a} \cdot \mathbf{I}_{t}^{\text {post }} \cdot \mathbf{I}_{r}^{\text {black }} \cdot \mathbf{I}_{g}^{\text {male }}\right)+\beta_{2}\left(P_{a} \cdot \mathbf{I}_{t}^{\text {post }} \cdot \mathbf{I}_{g}^{\text {male }}\right)+\beta_{3}\left(P_{a} \cdot \mathbf{I}_{t}^{\text {post }} \cdot \mathbf{I}_{r}^{\text {black }}\right) \\
& +\left(\mathbf{I}_{r}^{\text {black }} \cdot \mathbf{I}_{g}^{\text {male }} \cdot \mathbf{X}_{a t}^{\prime}\right) \Phi+\theta_{\text {rgt }}+\phi_{\text {rga }}+\tau_{a t}+\varepsilon_{\text {grat }} .
\end{aligned}
$$

In both equations, a full set of race-gender-time $(\theta)$, race-gender-geography $(\phi)$, and geographytime $(\tau)$ fixed effects are included. Race-gender-time fixed effects control flexibly for secular changes that could have differentially affected the health care utilization and mortality of each of the four

27. Specifically, we use $\max ($ distance $)-\left(\right.$ distance $\left._{s}\right)$ so that locations farthest from Tuskegee receive a proximity value of 0 . Distance is measured at the state level in the utilization data and at the SEA or county level for the mortality data. In the mortality data, distances are measured from the geographic centroid of each SEA to the centroid of Macon County, Alabama. For the NHIS outcomes, which are available at the state level, we use county-level black adult population statistics and geographic county centroids to create black population-weighted state centroids which are used to construct proximity as above. These centroids represent the average latitude and longitude of black individuals in each state based on the black population of counties (Haines 2010). 
groups. Race-gender-geography fixed effects absorb time-invariant location-specific factors that could differentially influence the health outcomes of each of the four groups. Local, time-varying shocks to health outcomes that affect all groups are absorbed by geography-time fixed effects.

In utilization regressions at the individual level, the vector $\mathbf{X}$ includes income, education, age, whether or not the individual owns a telephone, marital status, as well as an indicator for ruralurban status. For mortality rates, measured at the SEA level, the model includes SEA-year fixed effects that control for the changing supply of healthcare across locations over time, provided those changes affected all demographic groups equally. We add supply measures (the prevalence of doctors, hospitals, and hospital beds; the presence of community health centers; the log of total government healthcare expenditures-Medicare, Medicaid, and veterans healthcare; and the $\log$ of Social Security expenditures), each interacted with black and male indicators, to allow for differences in the effects of these supply measures on each group over time. Practically, they matter little for the estimates. (See Appendix Table A.3 for results without $\mathbf{X}$ variables.)

We limit our analysis to a window around the disclosure of 1969-1977 for utilization measures and 1968-1987 for mortality. We do not attempt to model the carry-on effects of TSUS to future cohorts of black men given that the identifying assumption behind the DDD approach becomes more tenuous as one moves out in time.

\section{IV.C. Identification}

The estimates of $\beta_{1}$ coming from equations (2) and (3) reflect the effect of the Tuskegee Study disclosure provided there are no other systematic shocks to black men that affected healthcare utilization and mortality correlated with proximity to Macon County, but not due to the timing of the study's disclosure. By conditioning on the fixed effects and covariates described above, these estimates flexibly control for the health penalty associated with being a black male in all years and for time-varying threats to identification such as national trends in incarceration and unemployment that affected all black men. ${ }^{28}$ Similarly, although access to care and insurance coverage for black men differed from other groups in this period, any time-invariant geographic differences in these factors are absorbed by the race-gender-location fixed effects. Location-year

28. In the Appendix, we show that our results are robust to controls for local measures of incarceration and unemployment as well. See Appendix Table A.5 columns (3) and (6). 
effects net out any time-varying health advantages or disadvantages associated with geography that affected all Americans, such as the rollout of Medicare and Medicaid and their various expansions, although we note that there is no major expansion or contraction of public insurance in or around 1972 that would serve to confound interpretation of our results. Because we also condition on supply-side healthcare measures in the mortality regressions, interacted with group indicators, our specification accommodates changes in healthcare supply that affected black men in particular. If our attempts to control for these changes are inadequate, most policy changes coinciding with the timing of the disclosure served to increase access for disadvantaged populations, particularly in the South, and would therefore bias our estimates towards zero. ${ }^{29}$

Together, these controls limit the scope for unobserved factors to those affecting only black men, but not black women or white men, in closer proximity to Macon County, Alabama, and only after 1972 .

\section{Results}

\section{V.A. Event Study Estimates}

We first present the results of event study versions of equations (2) and (3) in which we generate a coefficient for the interaction of proximity with black and male indicators for every year, each relative to 1972, as well as a coefficient for proximity interacted with a black indicator in each year and a coefficient for proximity interacted with a male indicator in each year, again relative to 1972. Specifically, we estimate:

$$
\begin{aligned}
Y_{\text {irgst }}= & \alpha+\sum_{n \neq 1972} \beta_{1}^{n}\left(P_{s} \cdot \mathbf{I}_{t=n} \cdot \mathbf{I}_{r}^{\text {black }} \cdot \mathbf{I}_{g}^{\text {male }}\right)+\sum_{n \neq 1972} \beta_{2}^{n}\left(P_{s} \cdot \mathbf{I}_{t=n} \cdot \mathbf{I}_{g}^{\text {male }}\right) \\
& +\sum_{n \neq 1972} \beta_{3}^{n}\left(P_{s} \cdot \mathbf{I}_{t=n} \cdot \mathbf{I}_{r}^{\text {black }}\right)+\mathbf{X}_{i}^{\prime} \Phi+\theta_{r g t}+\phi_{\text {srg }}+\tau_{s t}+\varepsilon_{\text {igrst }},
\end{aligned}
$$

and a similar equation for mortality. $\mathbf{I}_{t=n}$ is an indicator for each year (other than 1972), such that each $\beta$ coefficient represents the interaction of proximity and group indicators in year $n$.

29. We find no evidence that expenditure levels for these social programs exhibited a temporal or geographic pattern mirroring our main empirical results. In Appendix Table A.7, both hospital beds per capita and Medicare expenditures show a continuous increase over this time period, and more so in locations closer to Tuskegee. But there is no trend break in 1972 that would have induced utilization and mortality changes in that year. (See Appendix Figure A.8.) 
Figure IV, Panel A plots estimates of $\beta_{1}$, the difference across genders in the racial gap in healthcare utilization as a function of distance from Macon County, Alabama, relative to the difference in 1972, along with $95 \%$ confidence intervals. Panel B plots estimates of $\beta_{2}$, the gender gap in health care utilization for whites as a function of distance from Macon County, Alabama, relative to 1972. Panel $\mathrm{C}$ plots estimates of $\beta_{3}$, the difference in health care utilization for black women versus white women as a function of distance from Macon County, Alabama, relative to 1972. The set of pre-1972 $\beta_{1}$ coefficients are statistically indistinguishable from zero, with the exception for the first year (1969), but there is a sharp, statistically significant and sustained change beginning in 1972. Such an abrupt discontinuity after 1972 is not seen in the dynamic plot of $\beta_{2}$ or $\beta_{3}$ coefficients, providing evidence that we are not capturing a generic, location-based shock that affected other groups.

Panels D through F of Figure IV contain the event studies for mortality. (Recall that the mortality data have been grouped to measure biennial averages and thus results are relative to 1972/1973.) Just as in Panel A, the plotted $\beta_{1}$ coefficients in Panel D are not statistically significant in the pre-disclosure years. After the disclosure of the Tuskegee Study, however, the differences in age-adjusted chronic mortality rates for black men relative to white men, compared to black women relative to white women, (or black men relative to black women, compared to white men relative to white women) increase with proximity to Macon County, Alabama, as indicated by the positive and statistically significant $\beta_{1}$ coefficients for years after 1973. Panels E and F, which plot the $\beta_{2}$ and $\beta_{3}$ coefficients for mortality, do not demonstrate an abrupt change in $1972 .{ }^{30}$

\section{V.B. Main Estimates}

The event studies contained in Figure IV are consistent with the notion that the Tuskegee disclosure had an impact on both health-seeking behaviors and mortality. To provide a summary measure of the impact of the Tuskegee Study revelation, and to subject our results to a battery of

30. Due to data limitations, we cannot acurately generate a longer pre-period for the mortality or utilization results. NCHS mortality data are available for earlier years, but the 1960 U.S. Census of Population, from which population counts would need to be derived for such an exercise, only reports local population counts by age and gender for the nonwhite population. In an attempt to construct a denominator for black mortality rates for years prior to 1968 , we limit the sample to locations where at least $60 \%$ of the 1960 non-white population was black. (Our results are robust to other choices of this cutoff.) Extended event study results (in Appendix Figure A.3) generated under these limitations also demonstrate insignificant and relatively flat pre-period estimates of the black male mortality penalty as a function of proximity to Macon County, Alabama. 
placebo and other robustness checks, we move to reporting the results of equations (2) and (3).

Table I reports the $\beta_{1}, \beta_{2}$, and $\beta_{3}$ coefficients in equation (2) for outcomes related to both health seeking behavior and mortality. We report four utilization outcomes of interest: how many outpatient physician interactions an NHIS respondent reported in the last 12 months ("Number Outpatient Visits"), whether an individual reported any outpatient visit with a physician in the last 12 months ("Any Outpatient Visit"), whether an individual reported having been admitted to a hospital in the past 12 months ("Any Hospital Admission"), and the number of nights spent in the hospital in the past 12 months ("Number Nights in Hospital"). We report four mortality outcomes of interest in Table I columns (5) to (8): the log and level of age-adjusted all-cause mortality and the log and level of age-adjusted chronic mortality for adults 45-74 years of age.

Estimated coefficients in column (1) of Table I indicate that black men experienced sharp declines in the probability of visiting a doctor in the years following 1972 as a function of their proximity to the Tuskegee Study's location. These estimates indicate that a standard deviation increase in proximity to the study's home county was associated with reduced outpatient interactions of 0.9 visits per year - approximately $22 \%$ of the pre-disclosure black male sample mean. From column (2), a one standard deviation increase in proximity to Macon County, Alabama, was associated with a 2.5 percentage point decline in the probability of having an outpatient doctor's visit, approximately $4 \%$ of the sample mean.

For hospitalization outcomes, estimates for $\beta_{1}$ in column (3) of Table I indicate a reduction in the probability of hospital admission for black men after 1972 of 1 percentage point per standard deviation of geographic distance. These results, although not statistically significant, indicate a post-Tuskegee Study disclosure reduction in acute medical care of $7 \%$ of the pre-disclosure mean. Although hospital admission rates went down, column (4) of Table I indicates black men appear to have had more advanced illness on presentation as reflected in longer hospital stays: black men experienced an increase in duration of stay of 0.5 nights per standard deviation. These estimates are large, representing $22 \%$ of the pre-1972 sample mean.

In Appendix Table A.2, we estimate this baseline equation on another healthcare utilization outcome less likely to have been affected by the Tuskegee disclosure: dental visits over the last 12 months. This outcome is available for a slightly truncated period of time (1969-1975), and shows black men in closer proximity to Macon County, Alabama, are slightly more likely to visit the 
dentist after 1972, although the estimated coefficient is not statistically significant. This result provides suggestive evidence that racial gaps in other forms of care stabilized after 1972 and that relative avoidance was specific to institutions most reminiscent of the Tuskegee Study.

In columns (5) and (7) of Table I, we estimate that a one-standard deviation increase in proximity to Tuskegee was associated with a post-1972 increase in both all-cause and chronic-cause age-adjusted mortality for black men of 3.7 and $4.5 \mathrm{log}$ points, respectively. When we estimate the model in levels, we find a one standard deviation increase is associated with 1.1 more deaths from any cause per 1000 population (column (6)) and 0.8 more deaths from chronic causes per 1000 population (column (8)). Based on our estimates, the elasticity of all-cause age-adjusted mortality with respect to physician visits ranges from 0.14 to 0.18 ; in other words, a $1 \%$ decrease in physician visits would increase mortality by approximately $0.14-0.18 \%{ }^{31}$ We view these estimates as an upper bound since men might have not only stopped interacting with physicians, they might have also delayed going to the hospital or heeding public health messaging around smoking, for instance (see Appendix Table A.2 column (2)). However, this value is consistent with similar estimates from Medicare and community health center expansion. ${ }^{32}$ Notably, we do not observe an effect of the Tuskegee disclosure on mortality rates from acute causes of death associated with violence, accidents, or other external causes (see Appendix Table A.6). In unreported results, the largest impacts appear to come from deaths due to cardiac conditions, diabetes, and respiratory diseases.

In almost all cases, estimates of $\beta_{2}$ and $\beta_{3}$ are insignificantly different from zero, implying no systematic post-1972 change in the gender gap in mortality for whites or the racial gap in mortality for women as a function of proximity to Macon County, Alabama. The estimated value of $\beta_{2}$ is positive and significant for the log mortality outcomes, but the significance of the coefficient belies two important observations. First, there is no change in the trajectory of the $\beta_{2}$ coefficient in 1972 (see Figure IV, Panel E). Rather, there is a low, positive rate of growth in the geographic mortality gradient for white men compared to white women with a slope an order of magnitude smaller than $\beta_{1}$. Second, unlike the $\beta_{1}$ effect, the $\beta_{2}$ effect is not centered on Macon County, Alabama, as

31. The elasticity was obtained by dividing a one standard deviation percent change in all-cause mortality by a one-standard deviation change percent change in outpatient physician interactions. The range is due to the inclusion or exclusion of veteran males from the utilization estimates; the higher elasticity is from a sample including veterans (whose utilization response was more muted).

32. Bailey and Goodman-Bacon (2015) show that exposure to a community health center in one's county of residence between 1965 and 1974 reduced adult all-cause mortality by as much as $2 \%$, implying an elasticity of approximately -0.18. Lichtenberg (2002) reports an elasticity of -0.095 . 
demonstrated in Appendix Figure A.5.

\section{V.C. Heterogeneous Effects}

In Table II, we explore heterogeneous effects by splitting the sample in various ways and reporting estimates of $\beta_{1}, \beta_{2}$, and $\beta_{3}$ for these subsamples. First, we explore the roles of income and education by dividing the sample at the median of black male household income (columns (1) and (2)) and at the median of black male education (columns (3) and (4)). Because the entire sample is divided at the black male median, above- and below-median samples are not equally sized. In both cases, we conjecture that black men lower on the socioeconomic ladder would respond more strongly to the Tuskegee Study disclosure if the channel for utilization effects is empathy or salience. Indeed, although the estimates of $\beta_{1}$ are negative and significant for both income groups, the point estimates for the effect of the Tuskegee disclosure on the health seeking behavior of poorer, less educated black men are significantly distinguishable from higher income, better educated black men at the $1 \%$ level. Black men in the lowest $50^{t h}$ percentile of the income distribution reduce their utilization by approximately 3 times more than black men in the top half of the income distribution. At the same time, black men with below-median education reduced their utilization by 1.9 visits per standard deviation of proximity to Macon County, Alabama, while the upper $50^{\text {th }}$ percentile of the education distribution exhibits a point estimate of approximately zero.

Next, we examine the moderating effect of black physicians on our baseline results in columns (5) and (6) of Table III. We hypothesize that the availability of a black physician would have reduced the rate at which black men downgraded their expectation of encountering a "good" doctor. For these results, we utilized data on the number of black and white physicians in each U.S. state from the 1970 U.S. Census of Population (U.S. Census Bureau 1970). Importantly, these counts are measured before, and are therefore not endogenous to, the 1972 disclosure. When we split the sample by places above and below the median number of black doctors (as a percentage of all doctors), we find suggestive, but weak, evidence for a moderating effect of black doctors. The coefficient for locations above the median is smaller than that for locations below this median, although these differences are not statistically significant. ${ }^{33}$

33. We do not find the same pattern if we use black physicians per black capita, suggesting that black men responded to the "whiteness" of the local medical profession, rather than to the availability of a black physician. 
Last, we divide the sample by marital status. In the absence of individual birth histories in the NHIS, we use marital status as a proxy for whether or not a woman had given birth. By 1960, 97\% of all births were in hospitals (Feldhusen 2000), and unmarried women had fewer children compared to married women. ${ }^{34}$ Thus, if marriage is a proxy for more childbirth-related experience with the healthcare sector, $\beta_{2}$ for unmarried black women should be more similar to $\beta_{1}$, the coefficient for black men. These results are tested in columns (7) and (8) of Table II. In estimates for $\beta_{1}$, we find that unmarried men have a more negative response to the news of the Tuskegee Study than their married counterparts, though the difference is relatively small and not statistically significant. But unmarried black women, represented by estimated coefficients on $P_{s} \cdot \mathbf{I}_{t}^{\text {post }} \cdot \mathbf{I}_{r}^{\text {black }}$ in column (8) of Table II, respond differently from married black women in column (7), both in sign and magnitude. Mirroring the behavior of black men, unmarried black women reduce health provider interactions in proportion to their proximity to Macon County, Alabama, whereas married black women continue to exhibit convergence in the South. For both married and unmarried women, the size of the coefficient is about a third of that for black men, albeit with opposing signs for married women.

\section{Threats to Identification and Robustness Checks}

We perform several tests to bolster a causal interpretation for our results. First, we test the robustness of our estimates by incorporating migration networks as an alternative measure of proximity and demonstrating similarly signed and statistically significant estimates. Second, we use placebo locations to show that the main results are specific to gradients of proximity to Macon County, Alabama. Third, we use placebo populations to demonstrate that the main results for both utilization measures and mortality rates are not observed when we estimate the baseline equations on younger population samples. We also show that our results are robust to a South-only sample; to dropping all control variables; to limiting to non-South observations; and to parametric estimating

34. In 1965, approximately $75 \%$ of black infants were born to married mothers (Akerlof, Yellen, and Katz 1996). In related work, Thomasson and Treber (2004) find that the hospitalization of childbirth in the 1930s and, in particular, the introduction of sulfa drugs may have disproportionately reduced maternal mortality among black women, despite the segregation of hospitals and otherwise racially inequitable access. Because older women in our sample would have given birth between 1925 and 1960 (roughly), a substantial share of them would have benefited from this "positive" healthcare experience. 
equations that allow for trends in unemployment and incarceration in the mortality specifications. We discuss the findings of the main robustness checks below, and the remainder are described in the Appendix.

\section{VI.A. Alternative Measures of Proximity}

The reduction in healthcare utilization and uptick in mortality for black men as a function of geographic proximity to Macon County, Alabama, is also apparent using an alternative measure of proximity. Table III, Panel A reports these checks for the utilization results regarding the number of physician interactions and Panel B provides analogous results for log age-adjusted chronic mortality. In both cases, we replace the baseline proximity measure, geographic proximity to Macon County, Alabama, with the percentage of 1935-1940 black migrants to a particular state or SEA who originated in Alabama. (All Alabama SEAs and the state of Alabama are excluded from this analysis.) We observe statistically significant differences in the post-1972 utilization of primary healthcare and in the post-1972 mortality rates for black men as a function of this variable as well. Specifically, we estimate that a $10 \%$ increase in the share of black migrants from Alabama reduces utilization by 1 interaction per year and increases mortality by approximately $2 \%$.

\section{VI.B. Permutation Tests}

To test whether the geographic gradients documented in our baseline interacted DDD results are specific to distance from Macon County, Alabama, we run placebo regressions, replacing the baseline proximity measure (proximity to Macon County, Alabama) with proximity to the geographic centroid of every other state or SEA and re-estimating the model. These regressions serve as placebo tests, evaluating whether we find the same (or stronger) utilization effects as a function of the gradient to other locations in the U.S. Figure V presents the distribution, in histogram form, of the estimated values of $\beta_{1}$ in each of these tests when the outcome is the intensive margin of primary care utilization (Panel A) and log age-adjusted chronic mortality (Panel B). The vertical line indicates the estimated coefficient from Table I when the proximity measure is the baseline proximity to Macon County, Alabama. In both cases, the value of the Macon County estimate is greater (in absolute value) than $96 \%$ of placebo estimates; other outcomes exhibit similar patterns.

For the mortality results, we can also display heat maps of the coefficient estimates of $\beta_{1}$ as well 
as $\beta_{2}$ and $\beta_{3 .}$. These results, contained in Appendix Figure A.5, Panel B, demonstrate that the handful of locations where the estimates for $\beta_{1}$ are greater than those using proximity to Macon County, Alabama, are also close geographically and thus highly correlated with the treatment. The coefficients for $\beta_{2}$ and $\beta_{3}$ using these alternative proximity measures exhibit a far smaller range of estimate values. For $\beta_{2}$, these values are largest in the North Central states, while $\beta_{3}$ values are actually smallest in the U.S. South.

\section{VI.C. Robustness Checks}

To evaluate whether the paper's measured impacts simply reflect a general southern effect, columns (2), (3), (6), and (7) of Table III restrict the analysis sample to southern residents only. This reduces the scope for identification threats to things correlated with geographic proximity to Macon County, Alabama, in particular, and not to the South in general. The estimated value of $\beta_{1}$ is relatively unchanged in these specifications compared to our baseline estimates, particularly when using geographic proximity as the treatment variable. In Appendix Table A.3, we include additional robustness checks for the utilization and mortality outcomes, including dropping the South entirely and adding interactions between region fixed effects and post, black, and male indicators. Results are similar to those presented in Tables I and III.

We next limit the sample to children under 14 years of age for both mortality and utilization results. The post-1972 difference in outpatient care for black and white male children exhibits no geographic gradient, nor does the difference in utilization for black male and black female children as evidenced by coefficients statistically indistinguishable from zero in column (4) of Table III. For mortality outcomes, there is no differential change in the mortality rate of black male children after 1972 as a function of proximity to Macon County, Alabama, although male children and black children, in general, experienced lower death rates along this geographic gradient. This result is based on a mortality outcome in levels (instead of logs) due to the large number of zeroes, but caution should still be used in interpreting these results given the small death counts compared to older age groups. The non-result for black male children is consistent with both a lower salience of the study's abuses for younger children and with results showing that black married women were seemingly unaffected by the study's disclosure. Although the perceptions of their fathers could feasibly have affected the demand for children's healthcare utilization, the non-result here may 
indicate that decision-making for children at this time was mostly driven by maternal preferences. Given these results, the scope of identification threats is narrowed substantially to those factors correlated with the primary care utilization and mortality rates of older black men centered on Macon County, Alabama, after 1972 which did not affect child mortality or children's healthcare utilization.

\section{Channels}

Our measure of how much trust one has in their doctor comes from the GSS, a repeated cross section extending from 1972 to the present. The earliest year questions were asked about doctors was 1998, when several questions were included. In particular, participants were asked about whether "doctor's judgment trusted" and whether "doctors deny me the treatment needed". As a placebo outcome, we also examine respondents' views on whether people, in general, can be trusted. ${ }^{35}$ Although we do not have data for both before and after the disclosure, we can test whether individuals living closer to Macon County, Alabama, exhibit greater post-disclosure mistrust. For this analysis, we ask whether there is a racial (gender) gap in medical trust that varies across genders (races) as a function of proximity to Macon County, Alabama. The estimating equation for survey responses for individual $i$ residing in state $s$ of race $r$ and gender $g$ is given by:

(5) Mistrust $_{\text {irgs }}=\alpha+\beta_{1}\left(P_{s} \cdot \mathbf{I}_{r}^{\text {black }} \cdot \mathbf{I}_{g}^{\text {male }}\right)+\beta_{2}\left(P_{s} \cdot \mathbf{I}_{r}^{\text {black }}\right)+\beta_{3}\left(P_{s} \cdot \mathbf{I}_{g}^{\text {male }}\right)+\tau_{s}+\theta_{\text {rg }}+\mathbf{X}_{i}^{\prime} \Lambda+\epsilon_{\text {irgs }}$

where $P_{s}$ is proximity to Macon County, $\tau$ represents a current state of residence fixed effect, and $\theta$ denotes race-by-gender fixed effects. State fixed effects ensure that $\beta$ coefficients capture the geographic gradient in mistrust for each demographic group net of state-specific attitudes common across all groups. The sample includes individuals at least 10 years of age at the time of the disclosure. ${ }^{36} X$ contains age, education, and marital status fixed effects. Standard errors

35. Individuals who replied "no" or "don't know" to the question of whether people can be trusted were coded as 1 and those who replied "yes" were coded as 0. A similar coding strategy was applied to the outcome variables for medical mistrust (measured on a four point Likert scale) so that the coefficients can be easily interpreted as marginal effects.

36. This implies that age in the sample ranges from 36 to 89, with an average in the mid-fifties. Note that if we restrict to age $<10$ in 1972 , those aged 18 to 35 in our sample, our coefficients on medical mistrust and deny treatment generally have the "wrong sign". 
are clustered at the level of treatment (state of residence). The results, contained in Table IV, demonstrate that black men exhibit a strong, statistically significant geographic gradient in mistrust of doctors and similar (though not statistically significant) concern regarding treatment denial. A one standard deviation increase in proximity to Macon County, Alabama, is associated with a 14 percentage point increase in medical mistrust and a similar increase in treatment denial suspicion among black men as compared to white men, net of such racial gaps for women. Note that $\beta_{2}$ (the geographic gradient in mistrust for white men as compared to white women) and $\beta_{3}$ (the gradient for black women compared to white women) are often oppositely signed and not significant. It is not the case that black men closer to Tuskegee are simply less trusting; $\beta_{1}$ in column (3) where the outcome is general mistrust is opposite signed and not statistically significant.

Finally, we have posited the impact of Tuskegee would be more poignant for individuals who had limited experience with the healthcare sector prior to the disclosure. To isolate the role of experience as a mitigating factor on belief formation, we examine the post-1972 differences in healthcare utilization between men who have served in the military versus those who have not, again as a function of proximity to Macon County, Alabama. To do so, we drop women from the utilization sample, add back veteran men, and replace $\mathbf{I}_{g}^{\text {male }}$ in equation (2) with an indicator variable for whether an individual was a non-veteran, i.e., never drafted or entered into the military.

Estimated coefficients from this modified specification, contained in Table V, indicate a marked geographic gradient in the veteran/non-veteran gap in primary care utilization in the years following the Tuskegee disclosure. This finding is restricted to black men (as evidenced by the null or oppositely signed $\beta_{2}$ coefficient). Although black men's utilization declined overall (see $\beta_{3}$ in columns (1) and (2)), this effect was far more pronounced for non-veterans. For example, veteran black males reduced the number of outpatient visits per year by 0.59 per thousand kilometer proximity to Macon County, Alabama, while nonveteran black males reduced their utilization by about one additional visit per year. ${ }^{37}$ There are several possible explanations for this observation, including that veteran black men may have expected doctors to treat them as "veteran patients" rather than as "black male patients" and were therefore less worried about facing discrimination. Nevertheless, the results for veterans are consistent with predictions from the multi-period model wherein past experience with the medical profession dampens the response to the news of Tuskegee.

37. Appendix Figure A.9 contains event study coefficients for the within-male comparision. 


\section{EFFECT ON LIFE EXPECTANCY}

The paper's baseline results for the mortality of older adults, aged 45-74, can be converted into predicted reductions in life expectancy. To do so, we use levels of all-cause mortality as the outcome in equation (3). Predictions based on the full complement of terms, including the interaction of

$P_{a} \cdot \mathbf{I}_{t}^{\text {post }} \cdot \mathbf{I}_{r}^{\text {black }} \cdot \mathbf{I}_{g}^{\text {male }}$ multiplied by $\widehat{\beta_{1}}$, reflect mortality with the Tuskegee Study revelation. Predictions based on equation (3), but without this product, reflect counterfactual mortality in the absence of the revelation. The average value of these predictions are weighted so that they reflect the mortality patterns of black men given their population distribution circa 1970. These predicted mortality rates allow us to construct abridged, current life tables, in the presence and absence of the Tuskegee revelation, as described in the London Health Observatory Technical Supplement (2010).

For black men in our sample, the observed life expectancy, conditional on reaching age 45, is 23.7 years. Counterfactual life expectancy in the absence of the calculated treatment effect is 25.2 , an increase of 1.5 years. This estimated decrease in the life expectancy of black men attributable to the Tuskegee revelation represents approximately $35 \%$ of the racial gap in male life expectancy in 1980 and $25 \%$ of the gender gap in black life expectancy at the same juncture (National Center for Health Statistics 1985). As a benchmark for these results, Black et al. (2015) find that migration to the North in the first waves of the Great Migration (1916-1932) resulted in decreased life expectancy at age 65 of at least 1.5 years. Because their most robust analysis is based on Medicare data, these authors do not provide a similar estimate for life expectancy at age 45. Another useful benchmark is the hypothetical removal of smoking, which has been projected to increase life expectancy of an 18-year old by 1.7 years (Stewart, Cutler, and Rosen 2009) .

\section{Conclusion}

The Tuskegee Study was one of the most egregious examples of medical exploitation in U.S. history. Our estimates indicate that the years immediately following the study's disclosure brought significantly lower utilization of both outpatient and inpatient medical services by older black men in closer geographic proximity to the study's subjects. The effects are particularly heightened among less-educated and lower income men, a socioeconomic profile shared by the men targeted by PHS investigators. Moreover, the reductions in healthcare utilization we document paralleled 
a significant increase in the probability that older black men died before the age of 75 . The data indicate no corresponding effects for younger black males or for white males or black women. Our results are robust to accounting for a wide range of policies, economic forces, and individual characteristics thought to shape health behaviors. These findings underscore the importance of trust for economic relationships involving imperfect information, including in the provision of medical care.

Although our study has focused on how Tuskegee generated mistrust and shaped demand for healthcare services by blacks, the Tuskegee example also revealed racial inequities inherent in the provision of healthcare. A modern literature indicates these inequities persist. For example, Hoffman et al. (2016) document false beliefs among medical students and residents regarding racebased biological differences in pain tolerance that resulted in racial differences in treatment. As long as biased beliefs, policies, and practices are still prevalent in the U.S. healthcare system, mistrust is a rational response that may continue to contribute to health disparities.

Marcella Alsan, Stanford University, NBER and BREAD

Marianne Wanamaker, University of Tennessee, NBER and IZA

\section{REFERENCES}

ABC News/Washington Post, ABC News/The Washington Post: Los Angeles Race Riots [dataset] (Cornell University, Ithaca, NY: Roper Center for Public Opinion Research, 1992). Accessed August 2015.

Adler, Nancy, Thomas Boyce, Margaret A. Chesney, Sheldon Cohen, Susan Folkman, Robert L. Kahn, and S. Leonard Syme, "Socioeconomic Inequalities in Health: No Easy Solution," Journal of the American Medical Association, 269 (1993), 124-163.

Aizer, Anna, and Laura Stroud, "Education, Knowledge and the Evolution of Disparities in Health," NBER Working Paper No.15840, 2010.

Akerlof, George, Janet Yellen, and Michael L. Katz, "An Analysis of Out-of-Wedlock Childbearing in the United States," Quarterly Journal of Economics,111 (1996), 377-317.

Almond, Douglas, Kenneth Y. Chay, and Michael Greenstone, "Civil Rights, the War on Poverty and Black-White Convergence in Infant Mortality in the Rural South and Mississippi," MIT Working Paper Series No. 07-04, 2006.

Alsan, Marcella, and Claudia Goldin, "Watersheds in Infant Mortality: The Role of Effective Water and Sewerage Infrastructure, 1880 to 1915," NBER Working Paper No. 21263, 2015.

American Cancer Society, "Colorectal Cancer Facts and Figures 2008-2010," Colorectal Cancer Statistics, 2008.

Bailey, Martha J., and Andrew Goodman-Bacon, "The War on Poverty's Experiment in Public Medicine: Community Health Centers and the Mortality of Older Americans," American Economic Review, 105 (2015), 1067-1104. 
Banerjee, Abhijit, and Esther Duflo, Poor Economics: A Radical Rethinking of the Way to Fight Global Poverty (New York: Public Affairs, 2011).

Becker, Gary, and Yona Rubinstein, "Fear and the Response to Terrorism: An Economic Analysis," Centre for Economic Performance Working Paper No. 1079, 2011.

Bhalotra, Sonia R., and Atheendar Venkataramani, "Shadows of the Captain of the Men of Death: Early Life Health Interventions, Human Capital Investments, and Institutions," IZA DP No. 6041, 2011.

Black, Dan A., Seth G. Sanders, Evan J. Taylor, and Lowell J. Taylor, "The Impact of the Great Migration on Mortality of African Americans: Evidence from the Deep South," American Economic Review 105 (2015), 477-503.

Blinder, Alan, "In Rural Alabama A Longtime Mistrust of Medicine Fuels A Tuberculosis Outbreak," The New York Times, 2016.

Bogart, Laura M., Glenn J. Wagner Jr., Harold D. Green, Matt G. Mutchler, David J. Klein, Bryce McDavitt, Sean J. Lawrence, and Charles L. Hilliard, "Medical Mistrust among Social Network Members may Contribute to Antiretroviral Nonadherence in African Americans Living with HIV," Social Science \&3 Medicine, 164 (2016) 133-140.

Boulware, L. Ebony, Lisa A. Cooper, Lloyd E. Ratner, Thomas A. LaVeist, and Neil R Powe, "Race and Trust in the Health Care System," Public Health Reports, 118 (2003), 358-365.

Brandon, Dwayne T., Lydia A. Isaac, and Thomas A LaVeist, "The Legacy of Tuskegee and Trust in Medical Care: Is Tuskegee Responsible for Race Differences in Mistrust of Medical Care?," Journal of the National Medical Association, 97 (2005), 951-956.

Brandt, Allan M., "Racism and Research: The Case of the Tuskegee Syphilis Study," The Hastings Center Report, 8 (1978), 21-29.

Byrd, Michael, and Linda A. Clayton, An American Health Care Dilemma: Race Medicine and Healthcare in the United States, 1900-2000, Volume II. (New York: Routledge, 2002).

Carlson, Elizabeth D., and Robert M. Chamberlain, "The Black White Perception Gap and Health Disparities," Public Health Nursing, 21 (2004), 372-379.

Cascio, Elizabeth, and Ebonya Washington, "Valuing the Vote: The Redistribution of Voting Rights and State Funds following the Voting Rights Act of 1965," Quarterly Journal of Economics, 129 (2014), 379-433.

Centers for Disease Control and Prevention, "HIV/AIDS in the United States: 1981-2000," Morbidity and Mortality Weekly Report, 50 (2001), 430-434.

Centers for Disease Control and Prevention, Compressed Mortality Files (CMF 1968-1988, Series 20, No. 2A, 2000) CDCWONDER Online, 2014.

Corbie-Smith, Giselle, Stephen B. Thomas, Mark V. Williams, and Sandra Moody-Ayers, "Attitudes and Beliefs of African Americans Toward Participation in Medical Research," Journal of General Internal Medicine, 14 (1999), 537-546.

Curtin, Lester R., and Richard J. Klein, "Direct Standardization (Age-Adjusted Death Rates)," Healthy People 2000 Statistical Notes, 6 (1995), 1-10.

Cutler, David, Adriana Lleras-Muney, and Tom Vogl, "Socioeconomic Status and Health: Dimensions and Mechanisms" in The Oxford Handbook of Health Economics, ed. S. Glied and P. Smith (Oxford, UK: Oxford University Press, 2011).

Deaton, Angus, "Policy Implications of the Gradient of Health And Wealth," Health Affairs, 21 (2002), 13-30.

Dupas, Pascaline, "Health Behavior in Developing Countries," Annual Review of Economics, 3 (2011), 425-449.

Fafchamps, Marcel, "Development and Social Capital," The Journal of Development Studies, 42 (2006), 1180-1198. 
Feldhusen, Adrian E., "The History of Midwifery and Childbirth in America: A Time Line," Midwifery Today, (2000), 1-2.

Freedman, Tovia, "Why Don't They Come to Pike Street and Ask Us? Black American Women's Health Concerns," Social Science and Medicine, 47 (1998), 941-947.

Gaston, Gina B., and Binta Alleyne-Green, "The Impact of African Americans' Beliefs About HIV Medical Care on Treatment Adherence: A Systematic Review and Recommendations for Interventions," AIDS Behavior, 17 (2013), 31-40.

Goodman-Bacon, Andrew, "Public Insurance and Mortality: Evidence from Medicaid Implementation," Working Paper, (2015).

Green, Bernard, Richard Maisiak, Min Qi Wang, Marcia F. Britt, and Nonie Ebeling, "Participation in Health Education, Health Promotion, and Health Research by African Americans: Effects of the Tuskegee Syphilis Experiment," Journal of Health Education, 28 (1997), 196-201.

Greif, Avner, "Reputation and Coalitions in Medieval Trade: Evidence on the Maghribi Traders," The Journal of Economic History, 49 (1989), 857-882.

Guiso, Luigi, Paola Sapienza, and Luigi Zingales, "Alfred Marshall Lecture: Social Capital as Good Culture," Journal of the European Economic Association, 6 (2008), 295-320.

Gutsell, Jennifer N., and Michael Inzlicht, "Empathy Constrained: Prejudice Predicts Reduced Mental Simulation of Actions During Observation of Outgroups," Journal of Experimental Social Psychology, 46 (2010), 841-845.

Haines, Michael, Historical, Demographic, Economic, and Social Data: The United States, 17902002, ICPSR Study No. 02896, 2010.

Halbert, Chanita Hughes, Benita Weathers, Ernestine Delmoor, Brandon Mahler, James Coyne, Hayley S. Thompson, Thomas Ten Have, David Vaughn, Bruce Malkowicz, and David Lee, "Racial Differences in Medical Mistrust among Men Diagnosed with Prostate Cancer," Cancer, 115 (2009), 2553-2561.

Hamilton, Barton, Andrews Hincapie, Robert A. Miller, and Nicholas W. Papageorge, "Innovation and Diffusion of Medical Treatment," Working Paper, 2016.

Heintzelman, Carol, "The Tuskegee Syphilis Study and Its Implications for the 21st Century," The New Social Worker, 10 (2003), 1-2.

Hoffman, Kelly M., Sophie Trawalter, Jordan R. Axt, and M. Norman Oliver, "Racial bias in pain assessment and treatment recommendations, and false beliefs about biological differences between blacks and whites," Proceedings of the National Academy of Sciences of the United States of America,113 (2016), 4296-4301.

Holt-Lunstad, Julianne, Wendy Birmingham, and Brandon Q. Jones, "Is There Something Unique about Marriage? The Relative Impact of Marital Status, Relationship Quality, and Network Social Support on Ambulatory Blood Pressure and Mental Health," Annals of Behavioral Medicine, 35 (2008), 239-244.

Hood, Kristina B., Alton Hart, Faye Belgrave, Raymond H. Tademy, and Randy A. Jones, "The Role of Trust in Health Decision Making Among African American Men Recruited From Urban Barber Shops," Journal of the National Medical Association, 104 (2012), 351-359.

Institute of Medicine, Unequal Treatment: Confronting Racial and Ethnic Disparities in Health Care (Washington, DC: 2003).

Jackson, James S., and Gerald Gurin, National Survey of Black Americans, ICPSR Study No. $08512,1999$.

Jones, James H., Bad Blood: The Tuskegee Syphilis Experiment (New York: Free Press, 1992).

Kaiser Family Foundation, "The Health Status of African American Men in the United States," Race, Ethnicity, \& Health Care Fact Sheet, \#7630 (2007). 
Kayaniyil, Sheena, Shannon Gravely-Witte, Donna E.Stewart, Lyall Higginson, Neville Suskin, David Alter, and Sherry L. Grace, "Degree and Correlates of Patient Trust in their Cardiologist," Journal of Evaluation in Clinical Practice, 15 (2009), 634-640.

Knack, Stephen, and Philip Keefer, "Does Social Capital have an Economic Payoff? A CrossCountry Investigation," Quarterly Journal of Economics, 112 (1997), 1251-1288.

LaVeist, Thomas A., Kim Nickerson, and Janice Bowie, "Attitudes about Racism, Medical Mistrust and Satisfaction with Care among African American and White Cardiac Patients," Medical Care Research Review, 57 (2000), 146-161.

Lichtenberg, Frank, "The Effect of Medicare on Health Care Utilization and Outcomes," Frontiers in Health Policy Research, 5 (2002), 27-52.

London Health Observatory, "Calculating Life Expectancy and Infant Mortality Rates-Mapping Health Inequalities Across London," Technical Supplement, 2010.

Maddux, William W., and Marilynn B. Brewer, "Gender Differences in the Relational and Collective Bases for Trust," Group Processes and Intergroup Relations, 8 (2005), 159-171.

Mandell, Gerald L, John E. Bennett, and Raphael Dolin, Mandell, Douglas, and Bennett's Principles and Practice of Infectious Diseases 7th edition, Volume 2. (London: Churchill Livingstone, 2009).

McCallum, Jan, Arekere Dhananjaya, Lee Green, Ralph Katz, and Brian Rivers, "Awareness and Knowledge of the U.S. Public Health Service Syphilis Study at Tuskegee: Implications for Biomedical Research," Journal of HealthCare for the Poor and Underserved, 17 (2006), 716733.

Minnesota Population Center and State Access Data Assistance Center, Integrated Health Interview Series: Version 5.0. Minneapolis: University of Minnesota, 2012, https://ihis.ipums.org/ihis/, date accessed January 12, 2015.

Murphy, Sherry L., Jiaquan Xu, and Kenneth D. Kochanek, "Deaths: Final Data for 2010," National Vital Statistics Reports, 61 (2013), 1-118.

National Center for Health Statistics, U.S. Decennial Life Tables for 1979-1981; Volume 1, Number 1 (Hyattsville, Md.: Department of Health and Human Services (PHS), 1985).

NBC, NBC News Poll: R.A.C.E.-Racial Attitudes and Consciousness Exam [USNBC1989-RACE] [dataset] (Storrs, CT: The roper Center for Public Opinion Research, 1989). Accessed August 2015.

Newkirk II, Vann, "A Generation of Bad Blood," The Atlantic, 2016.

Nunn, Nathan, and Leonard Wantchekon, "The Slave Trade and the Origins of Mistrust in Africa," American Economic Review,101 (2011), 3221-3252.

Quinn, Sarah, "Belief in AIDS as a Form of Genocide: Implications for HIV Prevention Programs for African Americans," Journal of Health Education, 28 (1997), s6-s11.

Sandman, David, Elisabeth Simantov, and Christina An, "Out of Touch: American Men and the Health Care System," Commonwealth Fund Men's and Women's Health Survey Findings, 2000.

Shavers, Vickie, L., Charles F. Lynch, and Leon F. Burmesiter, "Racial Differences in Factors that Influence the Willingenss to Participate in Medical Research Studies," Annals of Epidemiology, 12 (2002), 248-256.

Silber, Jeffrey H., Paul R. Rosenbaum, Richard N. Ross, Bijan A. Niknam, Justin M. Ludwig, Wei Wang, Amy S. Clark, Kevin R. Fox, Min Wang, Orit Even-Shoshan, and Bruce J. Giantonio, "Racial Disparities in Colon Cancer Survival: A Matched Cohort Study," Annals of Internal Medicine, 161 (2014), 845-854.

Singer, Tania, Ben Seymour, John P. O’Doherty, Klaas E. Stephan, Raymond J. Dolan, and Chris D. Frith, "Empathic Neural Responses are Modulated by the Perceived Fairness of Others," Nature, 439 (2006), 466-469. 
Smith, Tom, Peter Marsden, Michael Hout, and Jibum Kim, General Social Surveys, 1972-2014 [datafile] (Chicago: NORC at the University of Chicago [producer]; Storrs, CT: The Roper Center for for Public Opinion Research [distributor], 2015). Accessed May 2015.

Stewart, Susan T., David M. Cutler, and Allison B. Rosen, "Forecasting the Effects of Obesity and Smoking on U.S. Life Expectancy," New England Journal of Medicine, 361 (2009), 2252-2260.

Tabellini, Guido, "The Scope of Cooperation: Values and Incentives," Quarterly Journal of Economics, 123 (2008), 905-950.

Thanakijborisut, Yuthapoom, "Estimating Price Elasticity of Demand for Medical Care Services in Thailand," International Journal of Business and Economics, (2015), 19-39.

The New York Times, "The AIDS 'Plot' Against Blacks," May 12, 1992.

Thomas, Stephen B., and Sandra Crouse Quinn. "The Tuskegee Syphilis Study, 1932 to 1972: Implications for HIV Education and AIDS Risk Education Programs in the Black Community," American Journal of Public Health, 81 (1991), 1500-1501.

Thomasson, Melissa, and Jaret Treber. "From Home to Hospital: The Evolution of Childbirth in the United States 1927-1940," Explorations in Economic History, 45 (2004), 76-99.

Tuskegee Syphilis Study Legacy Committee, "Final Report of the Tuskegee Syphilis Study Legacy Committee," 1996.

U.S. Census Bureau, "Census of Population and Housing Vol. 1: Characteristics of the Population," (Washington, D.C.: Government Printing Office, 1970).

Vaidya, Varun, Gautam Partha, and Monita Karmakar, "Gender Differences in Utilization of Preventive Care Services in the United States," Journal of Women's Health, 21 (2012), 140-145.

Viera, Anthony J., Joshua M. Thorpe, and Joanne M. Garrett, "Effects of Sex Age and Visits on Receipt of Preventive Health Services: A Secondary Analysis of National Data," BioMed Central Health Services Research, 6 (2006), 1-8.

White, Robert M., "Misinformation and Misbeliefs in the Tuskegee Study of Untreated Syphilis Fuel Mistrust in the Healthcare System," Journal of the National Medical Association, 97 (2005), $1566-1573$.

Wiltshire, Jacqueline, Sharina D. Person, and Jeroan Allison, "Exploring Differences in Trust in Doctors Among African American Men and Women," Journal of the National Medical Association, 103 (2011), 845-851. 


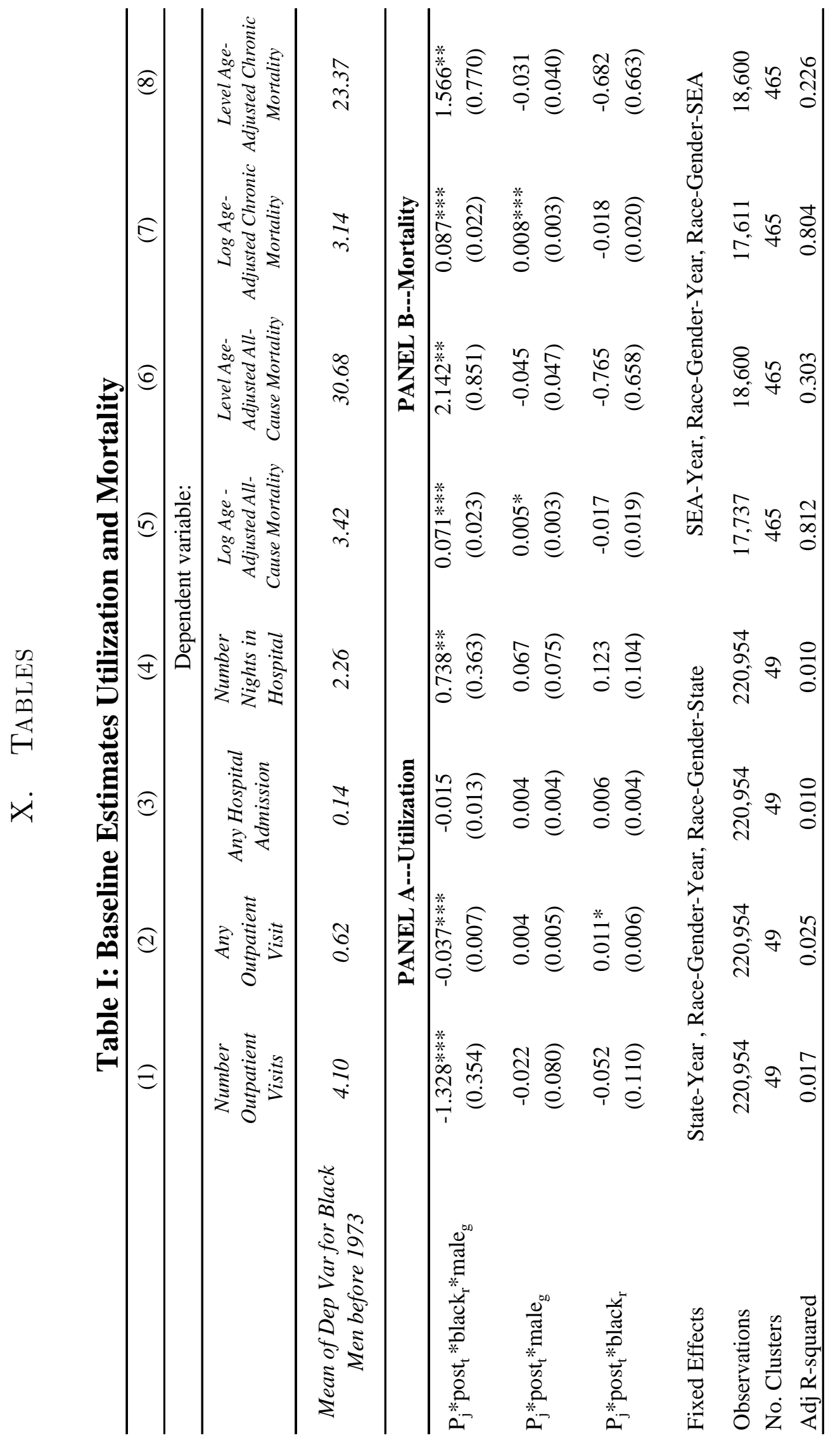




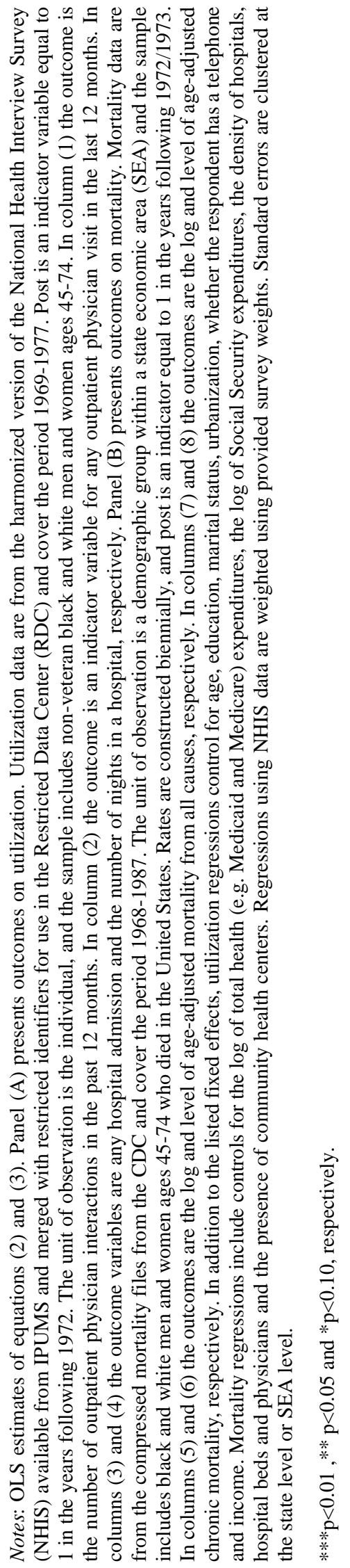




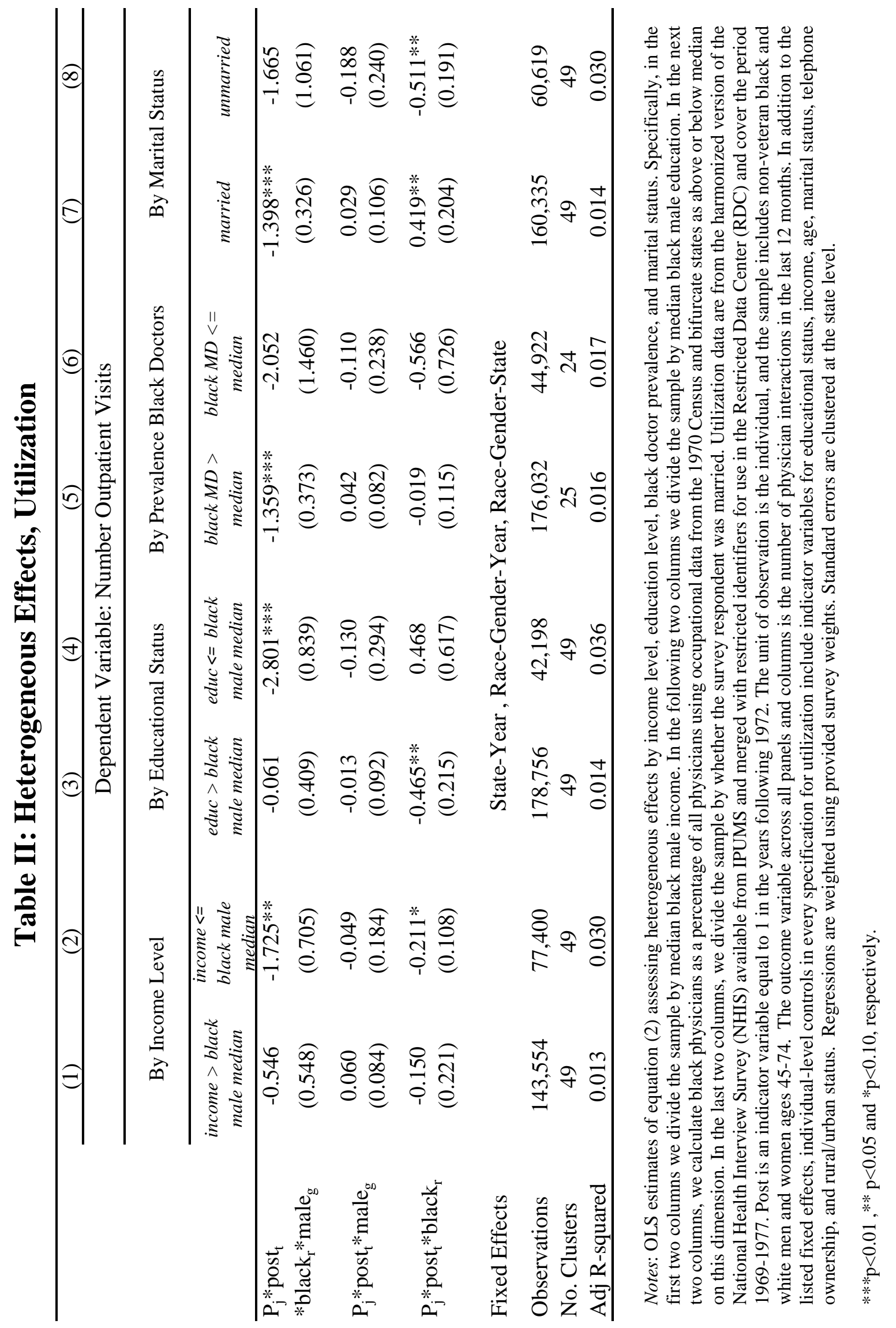




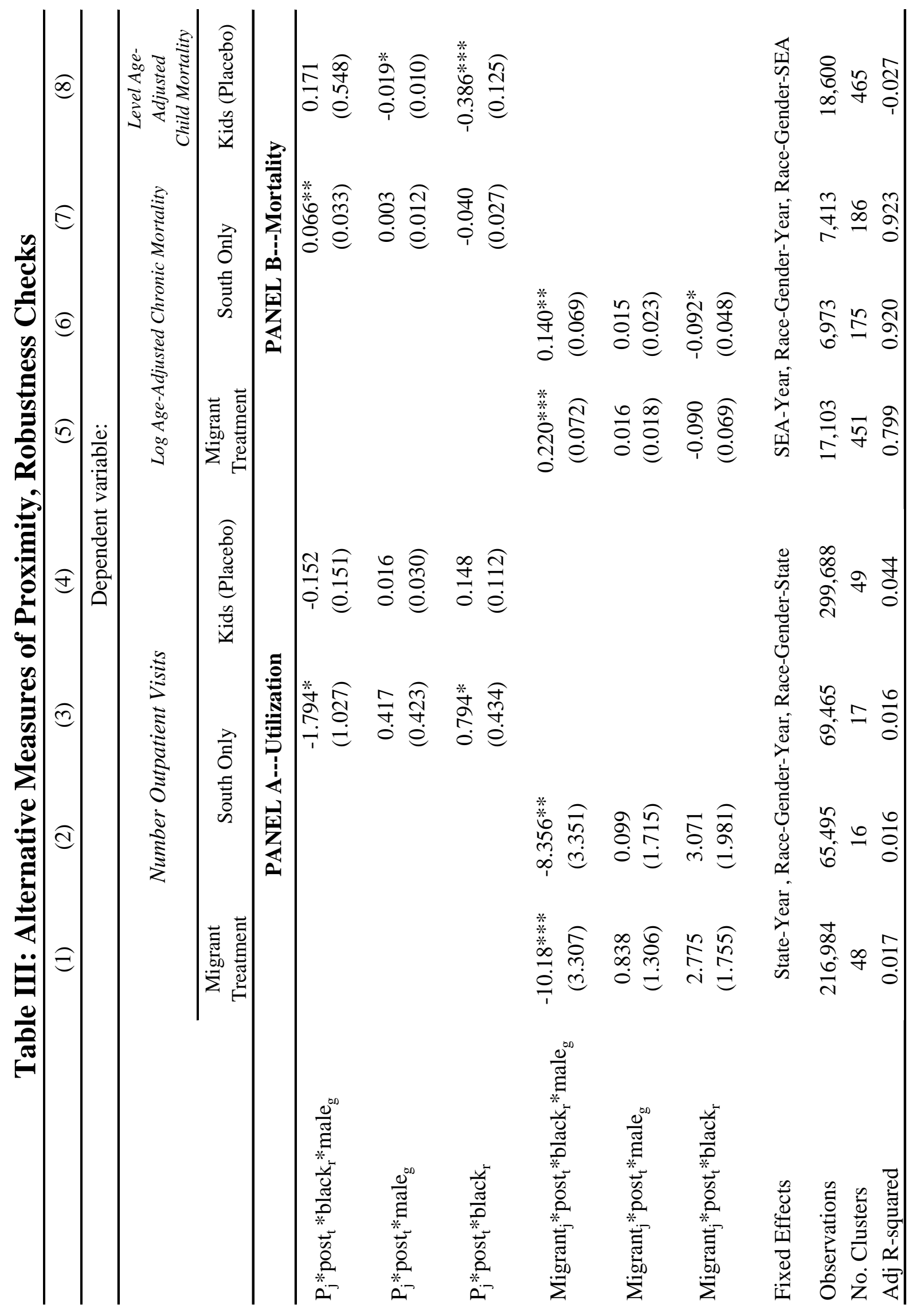




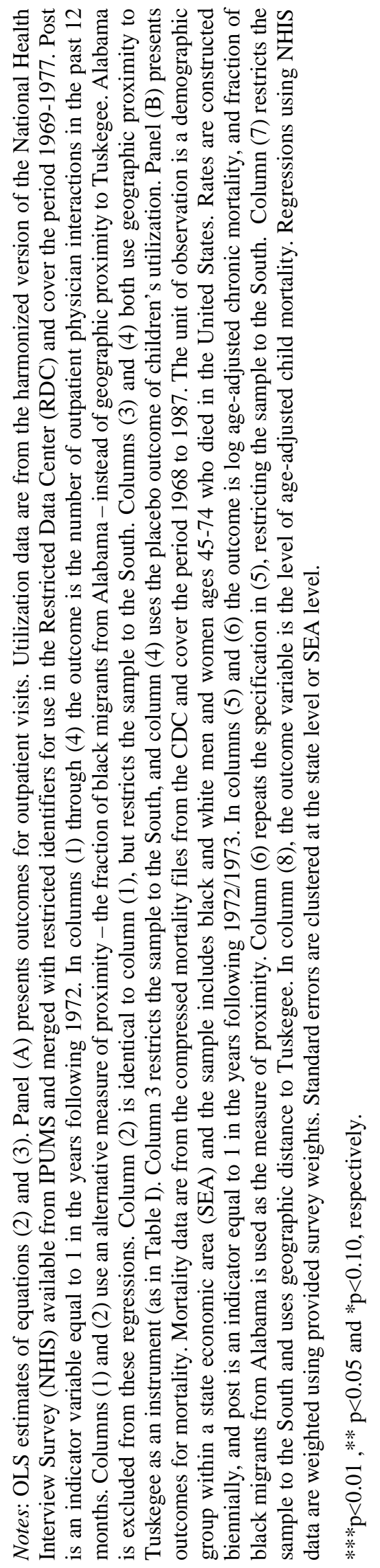




\section{Table IV: Effect of Tuskegee on Beliefs About Medical Care}

\begin{tabular}{|c|c|c|c|}
\hline & (1) & (2) & (3) \\
\hline Outcome & $\begin{array}{l}\text { Medical } \\
\text { Mistrust }\end{array}$ & Deny Treatment & $\begin{array}{l}\text { General } \\
\text { Mistrust }\end{array}$ \\
\hline \multirow{2}{*}{$\mathrm{P}_{\mathrm{j}} *$ black $_{\mathrm{r}} *$ male $_{\mathrm{g}}$} & $0.176^{* *}$ & 0.157 & -0.073 \\
\hline & $(0.071)$ & $(0.127)$ & $(0.197)$ \\
\hline $\mathrm{P}_{\mathrm{j}}{ }^{\mathrm{m}}$ male $_{\mathrm{g}}$ & $\begin{array}{l}-0.016 \\
(0.030)\end{array}$ & $\begin{array}{c}-0.002 \\
(0.039)\end{array}$ & $\begin{array}{l}-0.005 \\
(0.048)\end{array}$ \\
\hline $\mathrm{P}_{\mathrm{j}}$ black $_{\mathrm{r}}$ & $\begin{array}{l}-0.051 \\
(0.047)\end{array}$ & $\begin{array}{l}-0.024 \\
(0.115)\end{array}$ & $\begin{array}{c}-0.052 \\
(0.055)\end{array}$ \\
\hline Fixed Effects & \multicolumn{3}{|c|}{ State $_{1998,}$, Race$^{*}$ Gender } \\
\hline Observations & 801 & 801 & 801 \\
\hline Adj R-squared & 0.024 & 0.054 & 0.103 \\
\hline No. Clusters & 36 & 36 & 36 \\
\hline
\end{tabular}

Notes: OLS estimates of equation (4). The data are from the General Social Survey for the year 1998. The sample contains black and white males and females at least 10 years old in 1972 . The outcome variable for column (1) is whether the respondent disagrees with the statement that doctors can be trusted. The outcome variable in column (2) is whether the respondent believes they will be denied needed treatment by the medical profession. The outcome variable in column (3) is general mistrust (whether people, in general, can be trusted). In addition to the controls listed above, every specification includes indicator variables for age categories, marital status, state of current residence fixed effects, and indicators for being black, male, and the interaction. Standard errors are clustered at the state of residence level.

$* * * \mathrm{p}<0.01, * * \mathrm{p}<0.05, * \mathrm{p}<0.10$, respectively. 


\section{Table V: All Male Sample, Veterans vs. Non-Veterans}

\begin{tabular}{lcccc}
\hline & $(1)$ & $(2)$ & $(3)$ & $(4)$ \\
\hline \multicolumn{1}{c}{ Outcome } & Number & Any & Any Hospital & Number \\
& Outpatient & Outpatient & Nights in \\
& Visits & Visit & Admission & Hospital \\
\hline $\mathrm{P}_{\mathrm{j}}{ }^{*}$ post $_{\mathrm{t}}{ }^{*}$ black $_{\mathrm{r}}{ }^{*}$ nonvet $_{\mathrm{g}}$ & $-1.161^{* * *}$ & $-0.040^{* * *}$ & $-0.027 * * *$ & -0.417 \\
& $(0.347)$ & $(0.009)$ & $(0.007)$ & $(0.312)$ \\
$\mathrm{P}_{\mathrm{j}}{ }^{*}$ post $_{\mathrm{t}}{ }^{*}$ nonvet $_{\mathrm{g}}$ & $0.146^{* *}$ & 0.004 & 0.002 & 0.051 \\
& $(0.072)$ & $(0.005)$ & $(0.003)$ & $(0.056)$ \\
$\mathrm{P}_{\mathrm{j}}^{*}$ post $_{\mathrm{t}}{ }^{*}$ black $_{\mathrm{r}}$ & $-0.592^{* * *}$ & $-0.024 * *$ & -0.012 & 0.280 \\
& $(0.179)$ & $(0.011)$ & $(0.010)$ & $(0.247)$ \\
Fixed Effects & & & \\
Observations & State-Year, Race-Non-Veteran-Year, Race-Non-Veteran-State \\
No. Clusters & 135,635 & 135,635 & 135,635 & 135,635 \\
R-squared & 49 & 49 & 49 & 49 \\
\hline
\end{tabular}

Notes: OLS estimates of equation (2) testing differences between "experienced" (veteran) and "less experienced" (non-veteran) males in response to the disclosure of the Tuskegee study. Utilization data are from the harmonized version of the National Health Interview Survey (NHIS) available from IPUMS and merged with restricted identifiers for use in the Restricted Data Center (RDC) and cover the period 1969-1977. Post is an indicator variable equal to 1 in the years following 1972. The unit of observation is the individual, and the sample includes non-veteran and veteran black and white men ages 45-74. The outcome varies across columns and is given by the column heading. In addition to the listed fixed effects and controls in the table, individual-level controls in every specification for utilization include indicator variables for educational status, income, age, marital status, telephone ownership, and rural/urban status. Standard errors are clustered at the state level.

$* * * \mathrm{p}<0.01, * * \mathrm{p}<0.05$ and $* \mathrm{p}<0.10$, respectively. 


\section{Figures}

Figure I: Black-White Mortality Differences by Age and Sex

Panel A. Infant Mortality Rate

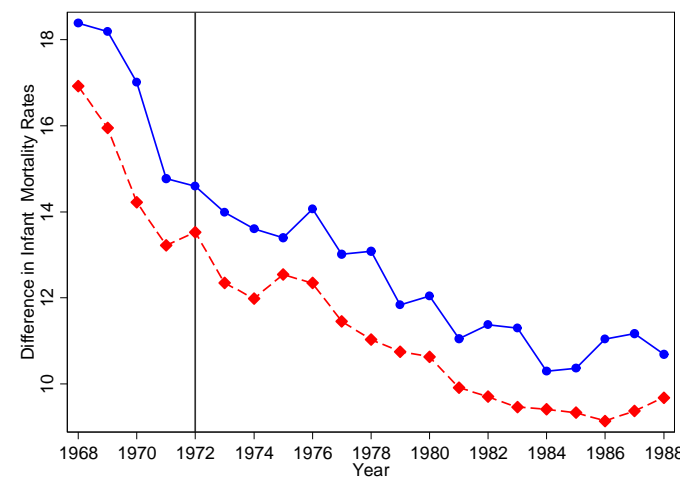

Panel C. 55-64 Mortality Rate

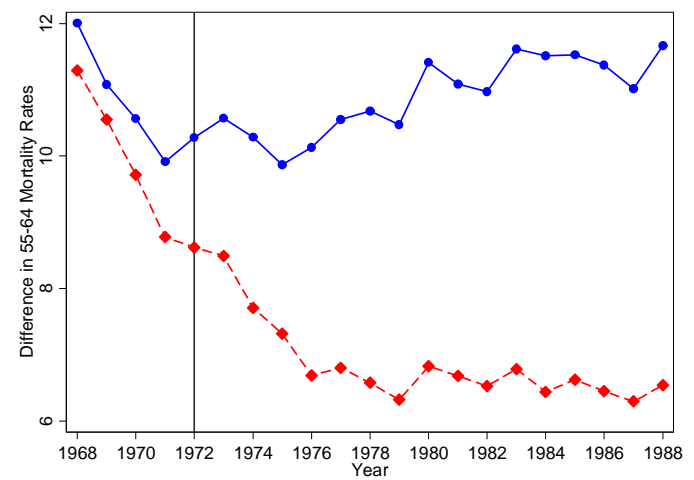

Panel B. Child Mortality Rate

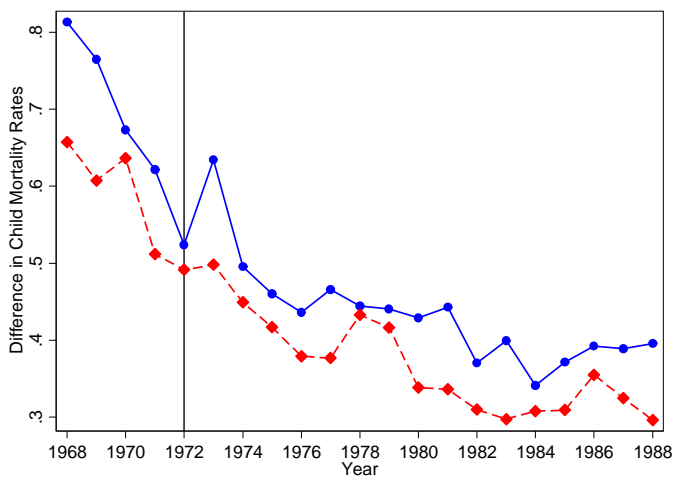

Panel D. 65-74 Mortality Rate

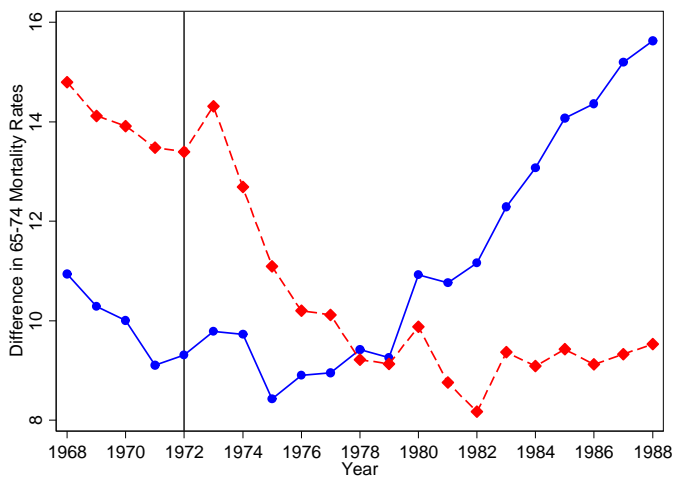

Notes: The data are from the CDC compressed mortality files and represent the black-white difference in age-specific mortality rates. Each mortality rate is calculated by dividing the number of deaths in the relevant population by the at-risk population (in thousands). The solid (blue) line represents the difference for males, and the dotted (red) line represents the difference for females. The vertical line represents the year "The Tuskegee Study of Untreated Syphilis in the Negro Male" was disclosed. For additional figures, including plots of all other age-specific mortality rates and South only, see the Appendix. 


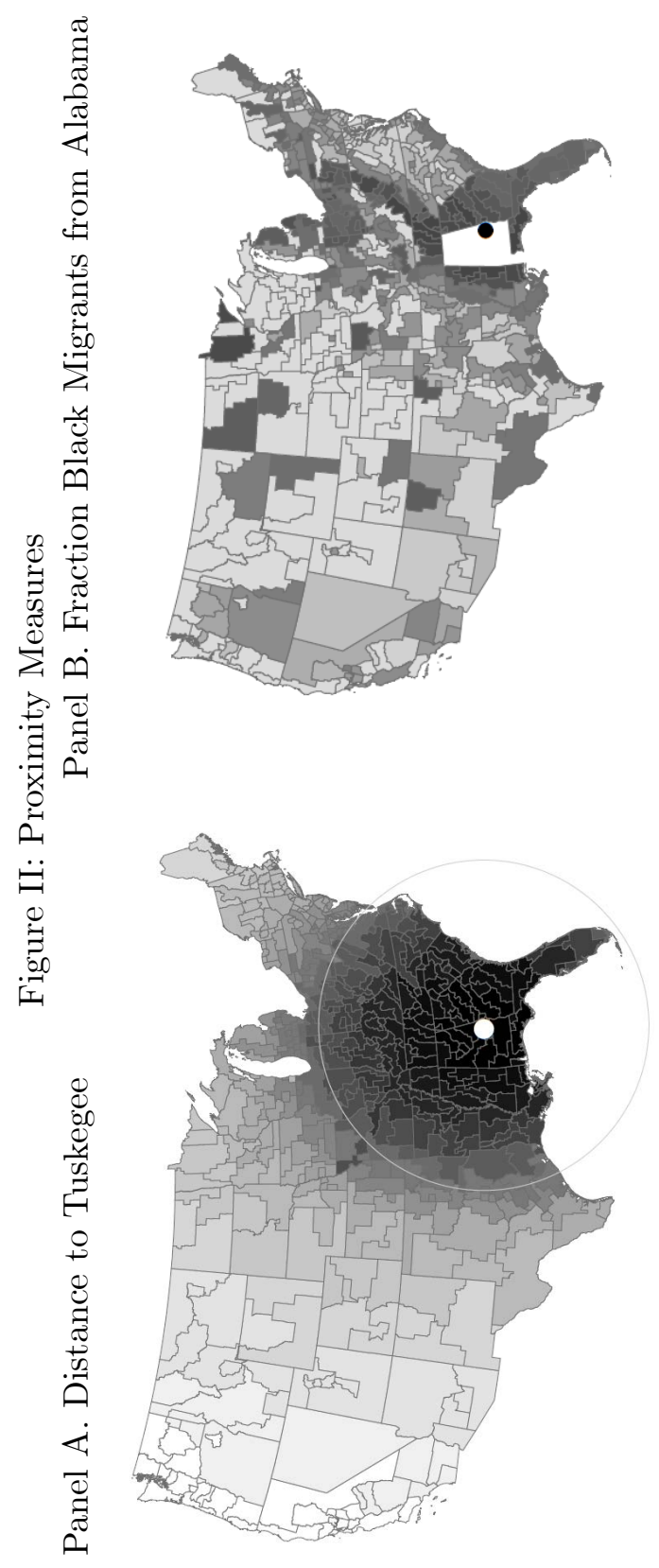

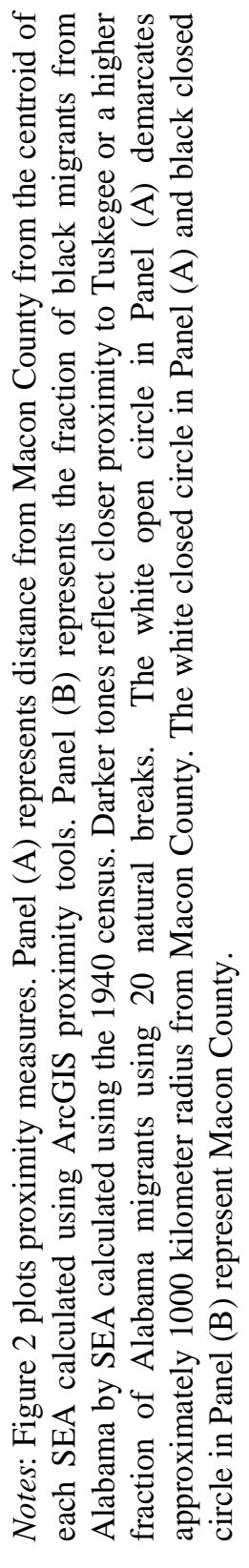


Figure III: Difference-in-Differences Coefficients and Geographic Gradients for Chronic Cause Mortality Panel A. $\beta$ - All Male Sample

Average DD Coefficient: 0.053

$95 \%$ CI: [0.034, 0.072]

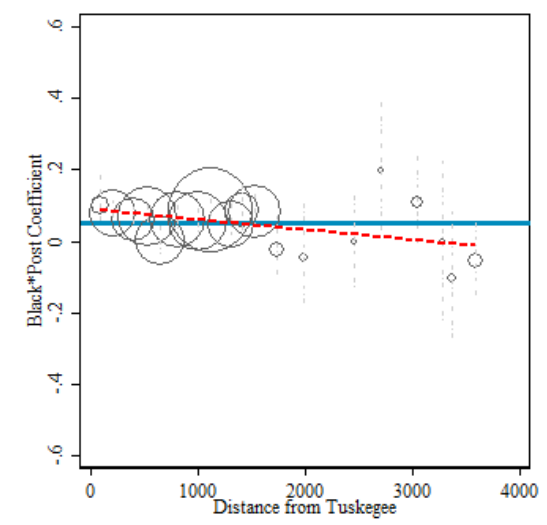

Panel B. $\beta$ - All Black Sample

Average DD Coefficient: 0.091

95\% CI: $[0.065,0.118]$

Panel C. $\beta$ - All Female Sample

DD Coefficient: -0.092

95\% CI: [-0.112, -0.072]

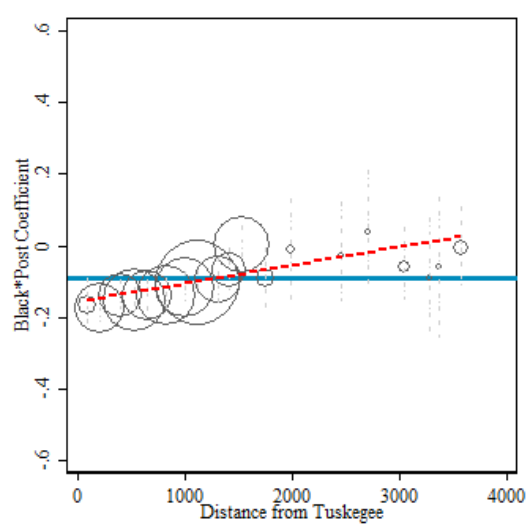

Panel E. $\beta$ - All Male Sample with False Post DD Coefficient: -0.006 95\% CI: [-0.040,0.027]

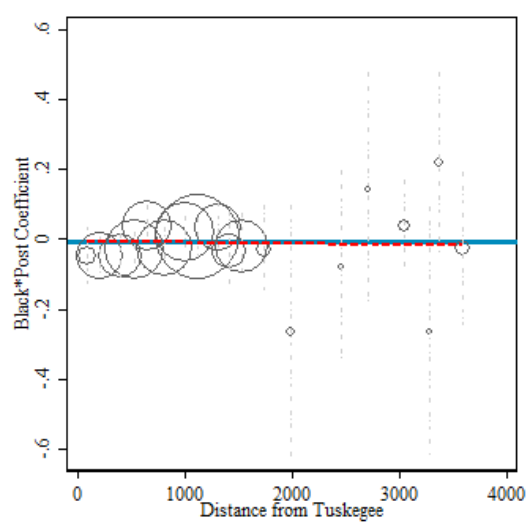

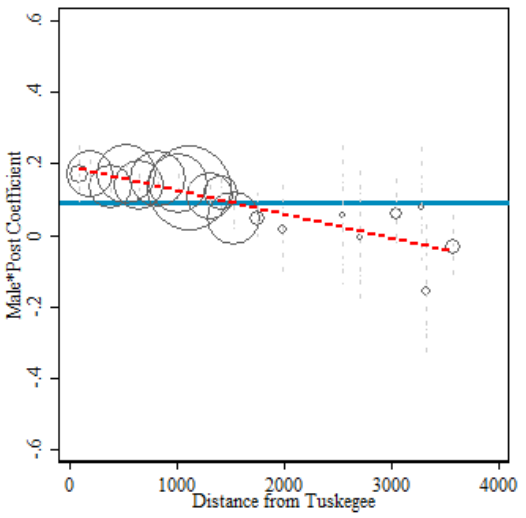

Panel D. $\beta$ - All White Sample

DD Coefficient: -0.054

95\% CI: [-0.064,-0.044]

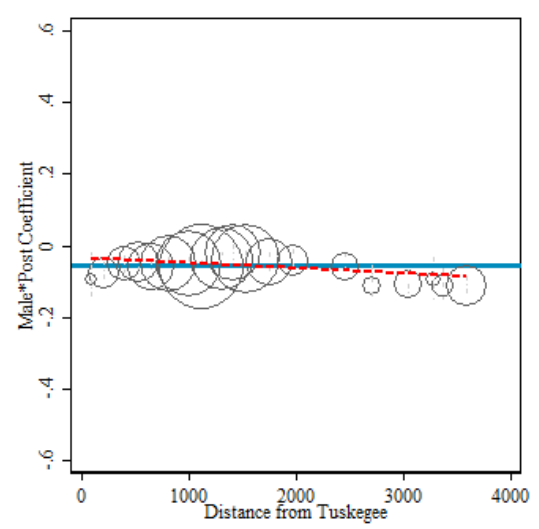

Panel F: $\beta$ - All Black Sample with False Post DD Coefficient: 0.014 95\% CI: [-0.036,0.063]

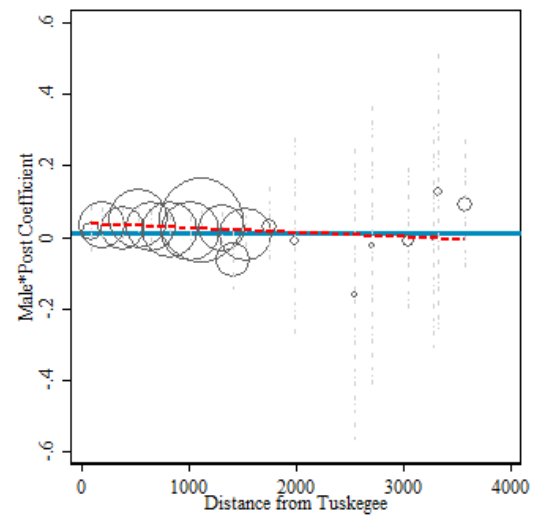


Notes: These figures plot $\beta$ coefficients from equation (1) estimated on various demographic group samples (all-male, all-black, all-white and all-female) as indicated by the figure headings and further subdivided into distance bins from Tuskegee. The outcome variable for each regression is the log of age-adjusted chronic mortality. Panels (A) and (B) plot $\beta$ coefficients on black*male*post in the all-male and all-black sample, respectively. Panels (C) and (D) plot $\beta$ coefficients on white*male*post and black*female*post in the all-white and all-female sample, respectively. Panels (E) and $(\mathrm{F})$ plot the same coefficients as in Panels (A) and (B), however, the time period of the analysis is restricted to the pre-1974 period with all observations after 1969 constituting the "post" period. SEAs were grouped into $K$ bins of 150 kilometers of distance from Macon County, Alabama each bin yielding a $\beta^{k}$. Bins in the middle of the country with less than 2,500 black men in 1970 were combined, and confidence intervals that were greater than 0.6 in absolute value were omitted so that the scale could be the same for all figures. Regressions for a given bin were weighted by the relevant SEA population (e.g. 45-74 year old males for the all-male sample), and the size of the bubble reflects the total weight of the respective treated population within each distance bin. Each $\beta^{k}$ coefficient is indicated by a bubble and the dashed vertical lines connected to the bubble denote its $95 \%$ confidence interval. The thick (blue) line depicts the average $\beta$ coefficient across the entire subsample. This average estimate and its $95 \%$ confidence interval are provided in the figure subheading. The line of best fit between the $\beta$ coefficients and distance from Tuskegee is drawn as a dashed (red) line. Data are from the CDC compressed mortality files and cover the period 1968 to 1987 unless otherwise indicated. Rates are constructed biennially, and post is an indicator equal to 1 in the years following 1972/1973 for Panels (A) through (D). Placebo post is an indicator equal to 1 in the years 1970/1971 and covers the period 1968 to 1973 . See main text and Appendix for further details on the data source and variable construction. 

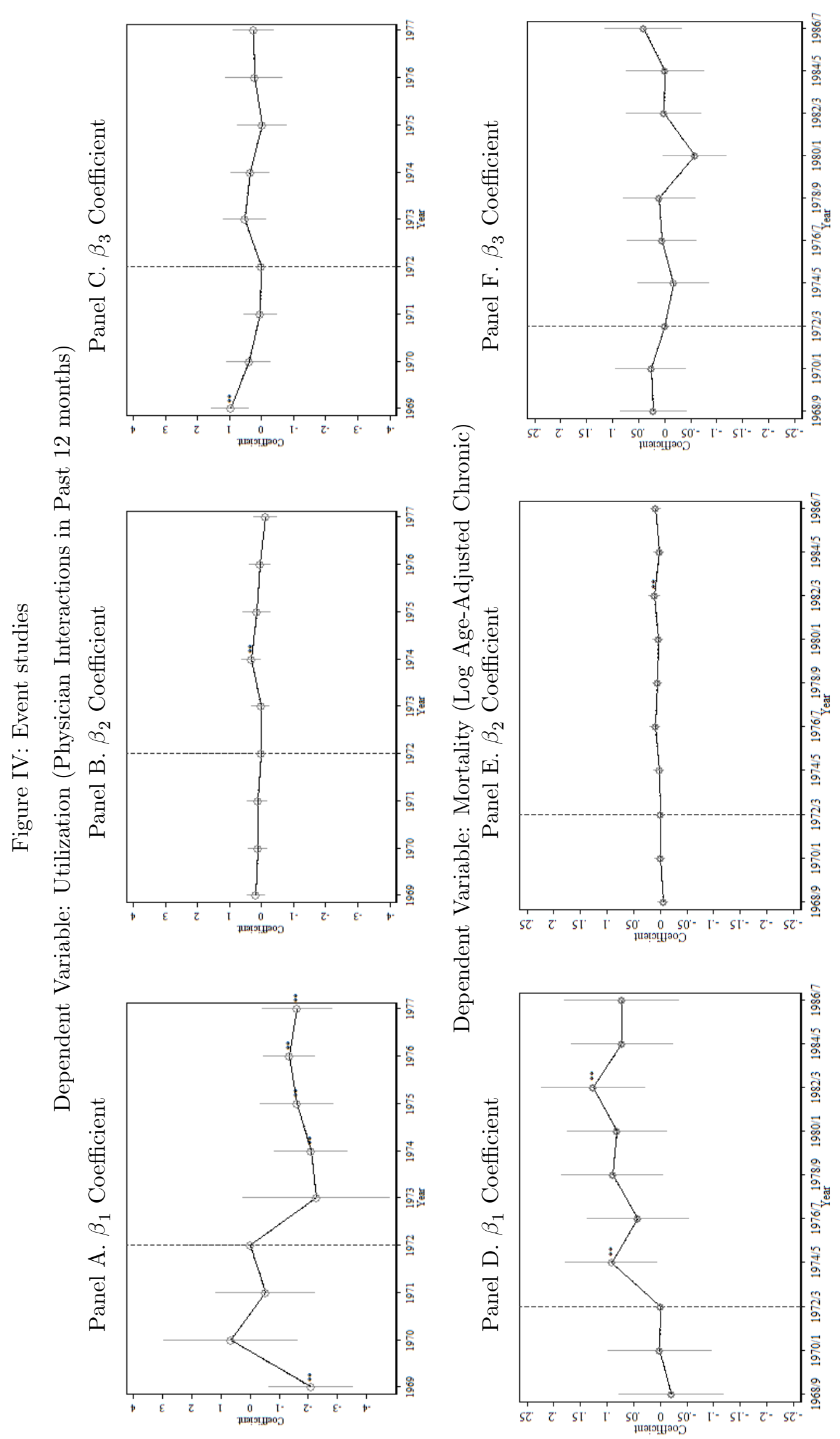


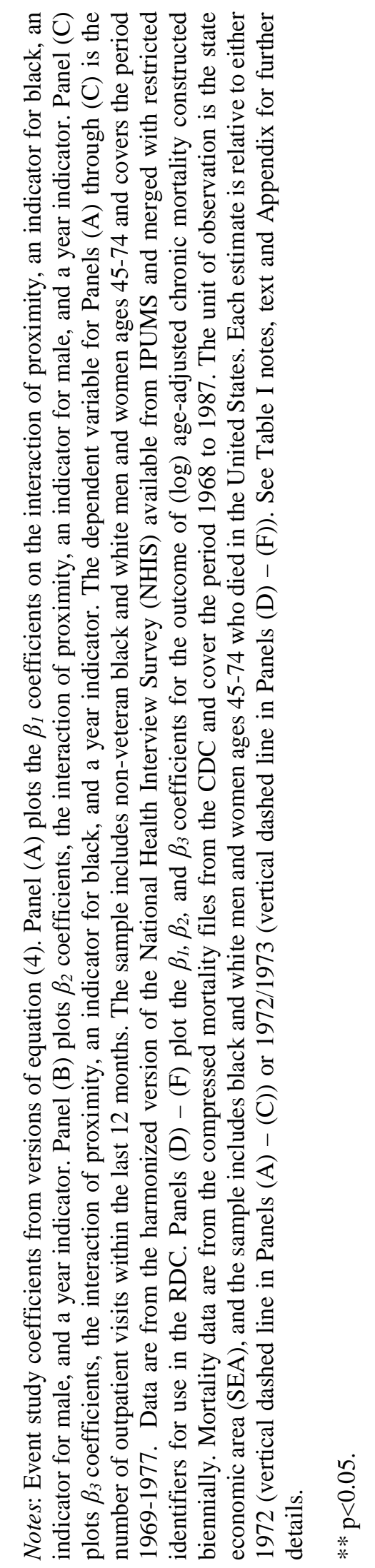


Figure V: Permutation Test

Panel A. Number Outpatient Visits

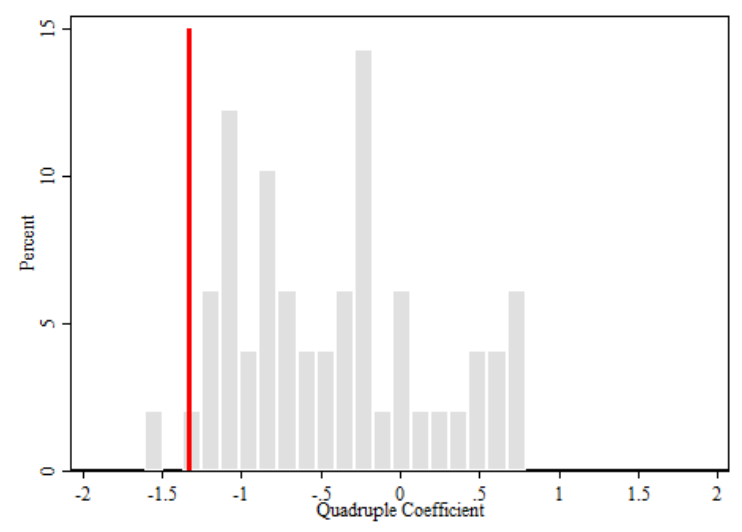

Panel B. Log Age-Adjusted Chronic Mortality

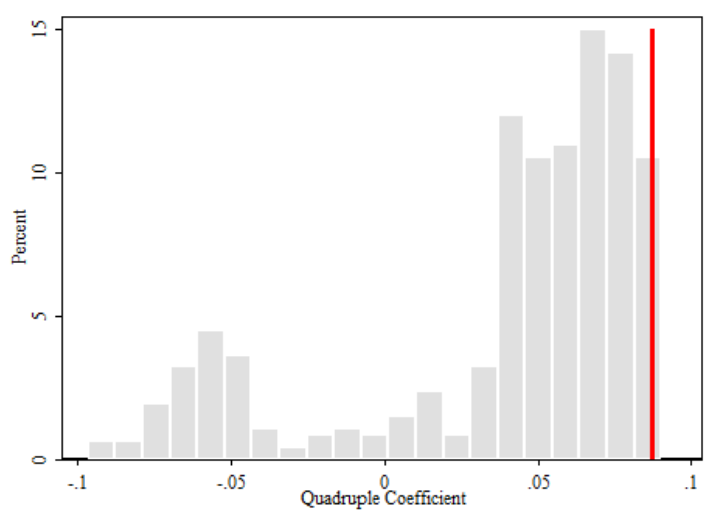

Notes: Frequency of the "false" $\beta_{1}$ coefficient estimated using distance from every other state (exclusive of Alabama) or SEA (exclusive of the one containing Macon County) in the sample and estimating equation (2) in Panel (A) or equation (3) in Panel (B). The vertical line denotes $\beta_{1}$ from baseline estimates using the true treatment distance (to Macon County, Alabama) as reported in Table I. 